\title{
Effect of fructans, prebiotics and fibres on the human gut microbiome assessed by 16S rRNA-based approaches: a review
}

\begin{abstract}
K.S. Swanson ${ }^{1}$, W.M. de Vos ${ }^{2,3}$, E.C. Martens ${ }^{4}$, J.A. Gilbert ${ }^{5,6}$, R.S. Menon ${ }^{7}$, A. Soto-Vaca ${ }^{7}$, J. Hautvast ${ }^{8 \#}$, P.D. Meyer ${ }^{9}$, K. Borewicz ${ }^{2}$, E.E. Vaughan ${ }^{10^{*}}$ and J.L. Slavin ${ }^{11}$

${ }^{1}$ Division of Nutritional Sciences, University of Illinois at Urbana-Champaign,1207 W. Gregory Drive, Urbana, IL 61801, USA; ${ }^{2}$ Laboratory of Microbiology, Wageningen University, Stippeneng 4, 6708 WE, Wageningen, the Netherlands; ${ }^{3}$ Human Microbiome Research Programme, Faculty of Medicine, University of Helsinki, Haartmaninkatu 3, P.O. Box 21, 00014, Helsinki, Finland; ${ }^{4}$ Department of Microbiology and Immunology, University of Michigan, 1150 West Medical Center Drive, Ann Arbor, MI 48130, USA; ${ }^{5}$ Microbiome Center, Department of Surgery, University of Chicago, Chicago, IL 60637, USA; ${ }^{6}$ Bioscience Division, Argonne National Laboratory, 9700 S Cass Ave, Lemont, IL 60439, USA; ${ }^{7}$ The Bell Institute of Health and Nutrition, General Mills Inc., 9000 Plymouth Ave N, Minneapolis, MN 55427, USA; ${ }^{8}$ Division Human Nutrition, Department Agrotechnology and Food Sciences, P.O. Box 17, 6700 AA, Wageningen University; ${ }^{9}$ Nutrition E Scientific Writing Consultant, Porfierdijk 27, 4706 MH Roosendaal, the Netherlands; ${ }^{10}$ Sensus (Royal Cosun), Oostelijke Havendijk 15, 4704 RA, Roosendaal, the Netherlands; ${ }^{11}$ Department of Food Science and Nutrition, University of Minnesota, 1334 Eckles Ave, St. Paul, MN 55108, USA; elaine.vaughan@sensus.nl; \#Emeritus Professor
\end{abstract}

Received: 27 May 2019 / Accepted: 15 December 2019

(c) 2020 Wageningen Academic Publishers

\section{OPEN ACCESS @(i) (2) REVIEW ARTICLE}

\begin{abstract}
The inherent and diverse capacity of dietary fibres, nondigestible oligosaccharides (NDOs) and prebiotics to modify the gut microbiota and markedly influence health status of the host has attracted rising interest. Research and collective initiatives to determine the composition and diversity of the human gut microbiota have increased over the past decade due to great advances in high-throughput technologies, particularly the 16S ribosomal RNA (rRNA) sequencing. Here we reviewed the application of $16 \mathrm{~S}$ rRNA-based molecular technologies, both community wide (sequencing and phylogenetic microarrays) and targeted methodologies (quantitative PCR, fluorescent in situ hybridisation) to study the effect of chicory inulin-type fructans, NDOs and specific added fibres, such as resistant starches, on the human intestinal microbiota. Overall, such technologies facilitated the monitoring of microbiota shifts due to prebiotic/fibre consumption, though there are limited community-wide sequencing studies so far. Molecular studies confirmed the selective bifidogenic effect of fructans and galactooligosaccharides (GOS) in human intervention studies. Fructans only occasionally decreased relative abundance of Bacteroidetes or stimulated other groups. The sequencing studies for various resistant starches, polydextrose and beta-glucan showed broader effects with more and different types of gut microbial species being enhanced, often including phylotypes of Ruminococcaceae. There was substantial variation in terms of magnitude of response and in individual responses to a specific fibre or NDO which may be due to numerous factors, such as initial presence and relative abundance of a microbial type, diet, genetics of the host, and intervention parameters, such as intervention duration and fibre dose. The field will clearly benefit from a more systematic approach that will support defining the impact of prebiotics and fibres on the gut microbiome, identify biomarkers that link gut microbes to health, and address the personalised response of an individual's microbiota to prebiotics and dietary fibres.
\end{abstract}

Keywords: nutrition, intestine, inulin, microbiota, health 


\section{Introduction}

Dietary fibres are acknowledged worldwide for their positive impact on health and well-being. Besides the well-known benefits on improved digestive health or bowel function, there are novel insights for the role of fibres in preventing obesity, reducing stress, supporting immunity, amongst other benefits (Canfora et al., 2015; Koh et al., 2016; Slavin, 2013; Stephen et al., 2017; Van de Wouw et al., 2018). The definitions of dietary fibres differ between countries or regions and include chemical properties as well as physiological effects, and some regions have specific definitions for isolated or synthetic fibres as opposed to those inherent in foods. The US Food and Drug Administration (FDA) has recently revised the nutrition facts label for foods and dietary supplements, and included a definition for the isolated/synthetic fibres, i.e. '... isolated or synthetic non-digestible carbohydrates (with three or more monomeric units) that FDA determines to have a physiological effect that is beneficial to human health'(FDA, 2016). Thus, the non-digestible carbohydrates must go through an US FDA approval procedure to be labelled as dietary fibre in the US. The European Union also has a fibre definition: 'carbohydrate polymers with three or more monomeric units, which are neither digested nor absorbed in the human small intestine' and 'which have been obtained from food raw material by physical, enzymatic or chemical means and which have a beneficial physiological effect demonstrated by generally accepted scientific evidence' (EC, 2011). A CODEX definition for fibre was established in 2010 (FAO/WHO, 2010). Some nondigestible oligosaccharides (NDOs), i.e. saccharide polymers containing a small number of monosaccharides (typically 3-10), may also be classified as fibres depending on the country's regulation. A specific subset of fibres or NDOs can selectively stimulate certain gut microbiota species and those fibres are termed as prebiotics, a term coined in 1995 (Gibson and Roberfroid, 1995). The most recent definition of prebiotic by International Scientific Association of Probiotics and Prebiotics (ISAPP) is 'a substrate that is selectively utilised by the host microorganisms conferring a health benefit' (Gibson et al., 2017). There are increasing numbers of (potential) dietary fibres and prebiotics on the food market, which may be isolated from plants or manufactured by enzymatic and/or chemical means. To date, inulin-derived fructans from the chicory root are among the most thoroughly studied fibres recognised by ISAPP as prebiotic (Gibson et al., 2017).

Since the early days of prebiotic research, the use of prebiotic fibres has been commonly associated with promoting growth of Actinobacteria, mainly the genus Bifidobacterium in the human colon. In the initial studies on the microbial effects of inulin-type fructans, the focus has been on the bifidogenic effect, as this appeared to be the most prominent outcome based on cultivation (Gibson and Roberfroid, 1995;
Hidaka et al., 1986). Introduction of culture independent, $16 \mathrm{~S}$ ribosomal RNA (rRNA)-based methods and highthroughput sequencing techniques allowed for more extensive examination of the microbial community and the impact of dietary fibres (Falony et al., 2016; Hornung et al., 2018; Shetty et al., 2017). Application of omics approaches together with mechanistic studies pointed to existence of microbial networks and cross-feeding which explains the involvement of other colonic bacteria that convert lactate and acetate into butyrate, notably those belonging to the genera Anaerostipes, Anaerobutyricum (previously Eubacterium hallii), Eubacterium rectale and Ruminococcus bromii (Belenguer et al., 2006; Duncan et al., 2004; Shetty et al., 2018; Venkataraman et al., 2016). Thus, the wider community approach to study different aspects of fibre fermentation and prebiotic effects might be necessary to establish a link between microbiota composition and activity on the one hand, and host health on the other (Delcour et al., 2016).

A vast number of microbial species inhabits the human colon, mainly within bacterial phyla Bacteroidetes and Firmicutes, while minor phyla include Actinobacteria, Proteobacteria, Verrucomicrobia, besides the Archaea kingdom (King et al., 2019; Shetty et al., 2017). There is increasing evidence that individual variation in the colonic microbiota predisposes consumers to respond differently to the same diets, as well as to dietary fibres. Remarkably, obese or overweight individuals who had a reduced gut microbial gene richness, presented more pronounced impaired metabolism and low-grade inflammation (Le Chatelier et al., 2013). A subsequent dietary intervention with proteins and fibres including inulin improved the low gene richness and clinical phenotypes in the individuals, although, it was less effective for reducing inflammation parameters in individuals with lower gene richness (Cotillard et al., 2013). Analyses of several intervention studies on fibre/resistant starch/fructan revealed for the first time potential microbial biomarkers or signatures for dietary responsiveness in obese individuals with impaired metabolic health (Korpela et al., 2014a; Salonen et al., 2014). A similar approach using gut microbiota signatures from an 800 person cohort, was applied in the development of an algorithm that predicted personalised diets to successfully lower elevated post-meal glucose responses (Zeevi et al., 2015).

Research on 16S rRNA-based methods for investigating the effects of a variety of specific fibres, NDOs and prebiotic ingredients with emphasis on chicory-derived fructans on the human gut microbiota was first discussed in a workshop with experts in Chicago in 2016. The focus was on studies with children to adult human subjects, and with either specific added fibres or prebiotics. The outcome of the workshop forms the basis for this review. Although, it was recognised that there was considerable information to be 
learned from in vitro and animal research, the most relevant data can be derived from human studies. The main objective here is to review existing knowledge on the impact of the different added dietary fibres, NDOs and prebiotics on the diversity of the human faecal microbiota using various culture independent, 16S rRNA based technologies.

The focus of this review is a description of human clinical trials using prebiotics, NDOs or fibres with diverse objectives that utilised high-throughput approaches (16S rRNA amplicon sequencing, phylogenetic microarrays and metagenomic sequencing), as well as other $16 \mathrm{~S}$ rRNAbased methods (such as quantitative PCR). Searches were performed to identify human adult and children interventions whereby the effect of inulin-type fructans and other specific NDOs and dietary fibres on the colonic/faecal microbiota were investigated. Initially, a brief description of the 16S rRNA technologies and the key initiatives on human microbiome research are outlined. The specific fibres, NDOs and prebiotics included in this review are then introduced. This is followed by a comprehensive description of the key findings on the effects of these fibres on the faecal microbiota, as well as findings on other physiological parameters. The review concludes with perspectives on future research in this field, which may ultimately lead to strategies on how to obtain hard endpoints for fibres and prebiotics and to aid development of personalised nutrition approaches for specific microbiota and health effects (Figure 1).

\section{Technologies and initiatives for human gut microbiome}

Many of the early findings on the effects of prebiotics on gut microbiota were incomplete as a number of gut microbial species could not, and still cannot be cultured outside of the host. Despite improvements in the cultivation methods in recent years (Lagier et al., 2016; Lagkouvardos et al., 2017), the more laborious nature, especially of anaerobic culturing, still gives the preference

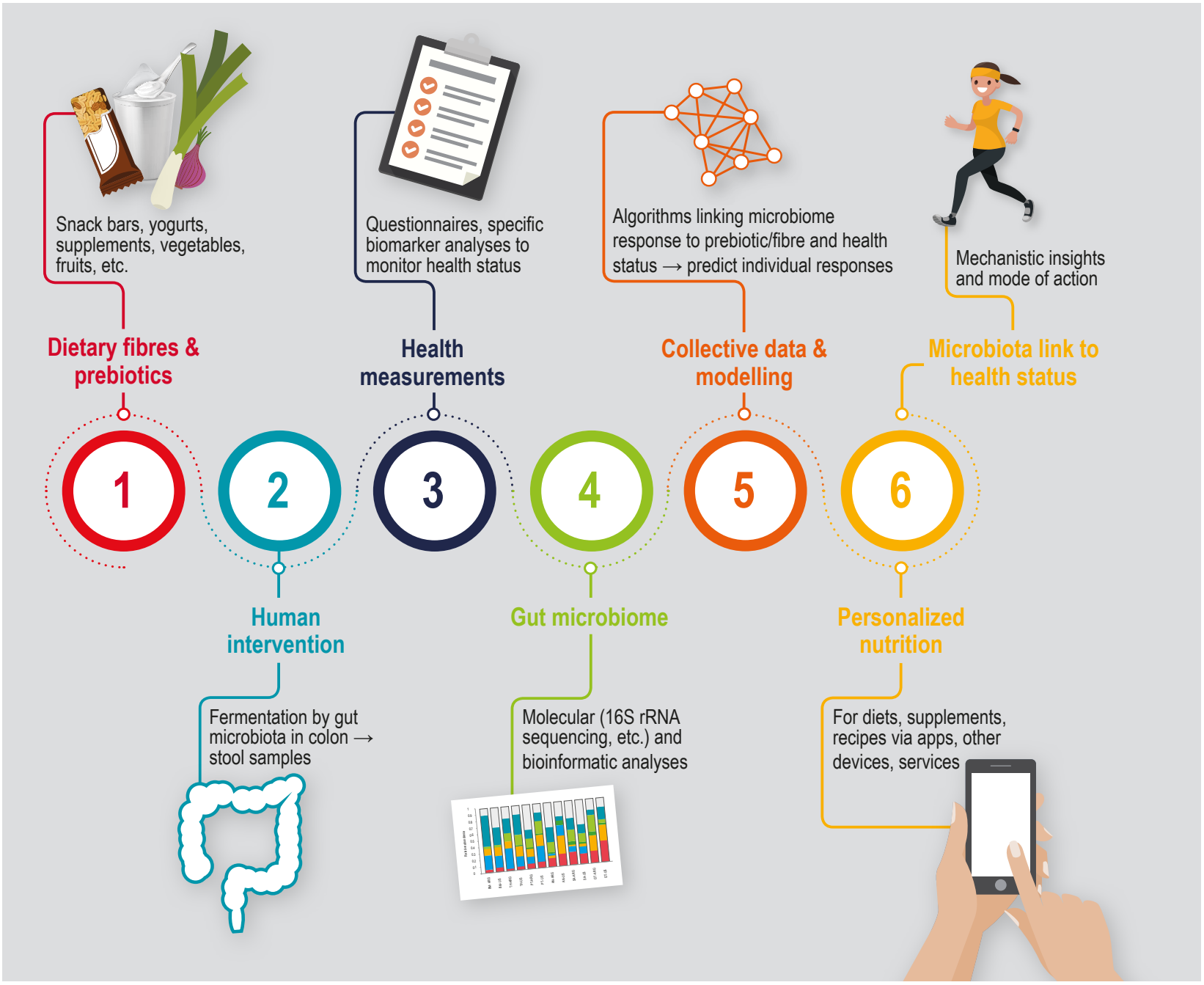

Figure 1. Scheme for investigating the impact of prebiotics and dietary fibres on the human gut microbiome in human interventions and linking changes to health status for future application such as in personalised nutrition. 
to culture independent, 16S rRNA-based technologies (Hiergeist et al., 2015). Analyses of the highly conserved bacterial 16S rRNA gene present in all bacteria gives an accurate estimation of the relative composition of complex microbial communities. Comparison of the 16S rRNA gene in approaches, such as quantitative (real time) PCR, fluorescent in situ hybridisation (FISH), and PCRdenaturing gradient gel electrophoresis (TGGE/DGGE) became widely employed in the late 1990's (reviewed by Fraher et al., 2012). Supplementary Table S1 provides a brief summary of the earlier cultivation-independent and -dependent methods.

An overview of the benefits and limitations of the key highthroughput cultivation independent techniques available in gut microbial ecology are presented in Table 1. The highthroughput methods developed in the last two decades include a variety of Next Generation Sequencing (NGS) techniques and phylogenetic microarrays. The microarrays, such as the Human Intestinal Tract Chip (HITChip ${ }^{\mathrm{pt}}$ ) are based on a set of fluorescently labelled oligonucleotide probes that hybridise with complementary nucleotide sequences. The HITChip ${ }^{\text {tw }}$ method is highly reproducible and fast, although the community assessment is limited by probe composition. The NGS methods offer parallel sequencing of PCR amplicons of the 16S rRNA gene, or fragmented total (meta)genomic DNA from the whole community (metagenomics/shotgun sequencing), or cDNA reverse transcribed from RNA (metatranscriptomics). A number of different second and third generation sequencing technologies can be used with sequencing taking place on beads (454 Pyrosequencing ${ }^{\oplus}$, Ion Torrent), slides (Illumina ${ }^{\circ}$ ), wells (PacBio), solid surface (SOLiD ${ }^{\mathrm{m}}$; nanopores (MinION/PromethION) or by electron microscopy (see review of Kumar et al., 2019).

Full understanding of the gut ecosystem requires a comprehensive view into microbiota structure, as well as knowledge on the microbiota activity and finally its functionality (Heintz-Buschart and Wilmes, 2018; Vandeputte et al., 2017). Thus, metagenomics with other 'omics' approaches such as proteomics and metabolomics, as well as their integrated form (meta-omics) can be used together with microbiota composition data to study activity. With any of these methods an enormous amount of information can be gathered even from a single experiment and proper data handling through extensive bioinformatics is essential (Kim and Tagkopoulos, 2018).

Table 1. High-throughput gut microbiota analyses technologies (Fraher et al., 2012; Kumar et al., 2019; Sekirov et al., 2010).

\begin{tabular}{|c|c|}
\hline Technique (Platform) & Advantages/disadvantages \\
\hline \multicolumn{2}{|l|}{ 16S rRNA gene sequencing or whole genome based } \\
\hline Second generation sequencing & Short read platforms (35-600 base-pairs (bp)). \\
\hline Pyrosequencing (454; Roche) & $\begin{array}{l}\text { Phylogenetic identification (very) good, PCR bias, labourious, extensive bioinformatics required. No } \\
\text { supplier support since } 2016 \text {, costly. }\end{array}$ \\
\hline Synthesis sequencing (Illumina MiSeq, & Phylogenetic identification (very) good, lower error rate than 454, longer run time, high output (1.2- \\
\hline MiniSeq, NextSeq, iSeq HiSeq, NovaSeq) & $\begin{array}{l}6,000 \mathrm{~Gb}), \text { PCR bias, laborious. Wide range of sequencing applications possible including amplicon } \\
\text { sequencing, metagenome and metatranscriptome. Extensive bioinformatics required, cost effective. }\end{array}$ \\
\hline Ion semiconductor sequencing (Ion Torrent) & Read lengths of 200 to $600 \mathrm{bp}$, output up to $50 \mathrm{~Gb}$, relatively low cost per base, relatively low throughput. \\
\hline $\begin{array}{l}\text { Nanoball Sequencing (BGISEQ-500, } \\
\text { MGISEQ-T7) }\end{array}$ & Similar to Illumina sequencing, low reagent consumption and low cost. \\
\hline Third generation sequencing & Real time, long read platforms (>1 kb). \\
\hline $\begin{array}{l}\text { Synthesis sequencing (PacBio (currently } \\
\text { owned by Illumina) SMRT: RSII, SEQUEL) }\end{array}$ & $\begin{array}{l}\text { Phylogenetic identification good, ultra-long read lengths, single molecule real time sequencing, and good } \\
\text { resolution of repetitive regions. High error rates (up to 13\%), fast throughput; high cost per base. }\end{array}$ \\
\hline $\begin{array}{l}\text { Nanopore (MinlON, GridION X5 and } \\
\text { PromethION) }\end{array}$ & $\begin{array}{l}\text { Highly portable to use in the field, very long reads (>2 Mb), label free, no amplification needed. High error } \\
\text { rates }(\sim 15 \%) \text {. }\end{array}$ \\
\hline \multicolumn{2}{|l|}{ Other technologies } \\
\hline $\begin{array}{l}\text { Microarrays (e.g. Human Intestinal Tract- } \\
\text { HITChip, Intestinal (I) chip, microbiota array) }\end{array}$ & $\begin{array}{l}\text { Phylogenetic identification very good; semi-quantitative, fast, and easy to use. Phylogenetic identification } \\
\text { possible, but novel groups not detected (no sequence on chip). Cross hybridisation, PCR bias, species } \\
\text { present in low levels can be difficult to detect; costly. }\end{array}$ \\
\hline \multicolumn{2}{|l|}{ Non-DNA based } \\
\hline Metabolomics & $\begin{array}{l}\text { Metabolic profiles for comparing communities functionally. More direct functional information on activity. } \\
\text { No taxonomic information. }\end{array}$ \\
\hline Metaproteomics & More direct functional information. No taxonomic information, less abundant proteins escape detection. \\
\hline Metatranscriptomics & $\begin{array}{l}\text { Insights in community-wide structure and function. Changes in gene expression can be detected. RNA is } \\
\text { much less stable than DNA. }\end{array}$ \\
\hline
\end{tabular}


The growing realisation of the profound impact of the human microbiota on health, together with the developments in technologies have led to the establishment of numerous large-scale human microbiome projects, and characterisation of microorganisms associated with human health and disease (Hadrich, 2018) (Table 2). Key initiatives included the Human Microbiome Project (HMP) Consortium, which among other body sites, studied the microbiome of faecal samples (Human Microbiome Project, 2012a,b). In Europe the MetaHIT project sequenced the human gut microbiomes from 124 European individuals showing that the total microbial gene set is about 150 times larger than our own human genome (Qin et al., 2010). The International Human Microbiome Consortium that was launched in October 2008 was established to coordinate the microbiome initiatives around the world. A more recent initiative is the American Gut project which is currently the largest, open source and crowd funded microbiome project in the world; the data are for the good of understanding and are shared both with participants and other scientists (Debelius et al., 2016). Still more recent efforts have used computational metagenome binning approach to give metagenome-assembled genomes to capture 1000s of uncultured gut species (Almeida et al., 2019). Microbiome studies continually generate new information: in one recent study using HITChip data with more than 1000 individuals, eight abundant genera were identified in the core microbiome shared by all, namely Bacteroides, Eubacterium, Faecalibacterium, Alistipes, Ruminococcus, Clostridium, Roseburia and Blautia (Shetty et al., 2017). Another recent study used a compilation of highly curated data from large scale projects to establish a reference database of healthy human gut microbiota and its correlations to different parameters in the metadata, including dietary data. The authors concluded that a healthy human gut is colonised by 8 phyla, 18 families, 23 classes, 38 orders, 59 genera and 109 species, of which 84 species could be referred as core and found in all sampled individuals (King et al., 2019). Thus, the knowledge generated by these initiatives and other research create an essential framework for understanding of the impact of specific fibres and prebiotics on the human gut ecosystem and ultimately will be linked to human health.

\section{Fructans, prebiotics and specific dietary fibres}

Topline information of the specific prebiotics, NDOs and fibres included in this review are described below and in Table 3, with specific emphasis on inulin. Inulin is a generic term that covers all $\beta$ - $(2,1)$-linked linear fructans with a variable degree of polymerisation (DP) and mostly one terminal glucose-unit. Although inulin-type fructans occur in a large variety of plants (Ritsema and Smeekens, 2003; Van Loo et al., 1995), chicory roots (Cichorium intybus L.) are the main source for industrial production. Chicory inulin and fructooligosaccharides (FOS), or chicory root fibre, is highly versatile due to the different chain lengths that are manufactured. Chicory inulin, FOS and mixes thereof are applied to a broad range of food applications from fibre or prebiotic enrichment to sugar and fat replacement, or texturizing purposes (Meyer et al., 2007, 2011; Schaafsma and Slavin, 2014). FOS with short chain length (scFOS) may also be synthesised from sucrose (Hirayama and Hidaka, 1993).

Table 2. Various gut microbiome projects around the globe (Stulberg et al., 2016).

$\begin{array}{lll}\text { Title / initiative } & \text { Country } & \text { Reference/ website } \\ \text { American Gut Project } & \text { USA } & \text { http://humanfoodproject.com/americangut } \\ \text { British Gut } & \text { UK } & \text { http://britishgut.org } \\ \text { Canadian Microbiome } & \text { Canada } & \text { http://www.cihr-irsc.gc.ca/e/39951.html } \\ \text { Elderly gut metagenomics project, ELDERMET } & \text { Ireland } & \text { http://eldermet.ucc.ie/ } \\ \text { Flemish Gut Flora project } & \text { Belgium } & \text { (Falony et al., 2016) } \\ \text { Human Gut Microbiome and Infections } & \text { China } & \text { https://www.nature.com/articles/nature11450 } \\ \text { Human Microbiome Consortium } & \text { USA-Global } & \text { http://hmpdacc.org } \\ \text { Human Metagenome Consortium } & \text { Japan } & \text { http://www.jchm.jp } \\ \text { International Human Microbiome Consortium (IHMC) } & \text { International } & \text { http://www.human-microbiome.org } \\ \text { Metagenomics of the Human Intestinal Tract (MetaHIT) } & \text { Europe } & \text { http://www.metahit.eu } \\ \text { MicroObes, Human Intestinal Microbiome in Obesity and } & \text { France } & \text { http://www.inra.fr/micro_obes_eng } \\ \text { Nutritional Transition } & & \\ \text { Korean Microbiome Diversity using Korean Twin Cohort Project } & \text { Korea } & \text { (Lim et al., 2014) } \\ \text { LifeLines } & \text { The Netherlands } & \text { https://lifelines.nl/home } \\ \text { MetaGenoPolis } & \text { France } & \text { http://www.mgps.eu/index.php?id=accueil } \\ \text { Michigan Microbiome Project } & \text { USA } & \text { http://microbe.med.umich.edu/about/research/michigan- } \\ & \text { microbiome-project } \\ \text { The Australian Jumpstart Human Microbiome Project } & \text { Australia } & \text { http://www.human-microbiome.org/index.php?id=30\#c77 }\end{array}$


Table 3. Description of inulin-type fructans, other non-digestible oligosaccharides and dietary fibres included in this review. ${ }^{1}$

\begin{tabular}{|c|c|c|}
\hline Fibre / prebiotic & Description & References \\
\hline \multicolumn{3}{|l|}{$\beta$-fructans / inulin-type fructans } \\
\hline Agave fructans & Extracted from agave, DP up to about 30; branched and highly branched fructans in 1:4.1 ratio & Carranza et al., 2015 \\
\hline Chicory native inulin & Inulin as extracted from chicory with DP 2-60 & Mensink et al., 2015 \\
\hline Chicory FOS & Produced from inulin by partial enzymatic hydrolysis, DP 2-8 & \\
\hline Chicory Ic-inulin/FOS & Long chain inulin produced from native chicory inulin, DP 10-60 & \\
\hline \multicolumn{3}{|c|}{ Chicory FOS/oligofructose } \\
\hline Chicory sc-inulin & Short chain inulin produced from native chicory inulin, DP 2-10 & \\
\hline ScFOS & Produced enzymatically from sucrose, DP $2-5$ & Hirayama and Hidaka, 1 \\
\hline Jerusalem artichoke inulin & Extracted from Jerusalem artichoke, DP range 2 to $>30$ & $\begin{array}{l}\text { Saengthongpinit and } \\
\text { Sajjaanantakul, } 2005\end{array}$ \\
\hline \multicolumn{3}{|c|}{ Other non-digestible oligosaccharides } \\
\hline AXOS & Isolated from wheat bran; xylan chains with a variable substitution level of arabinose side chains & Swennen et al., 2006 \\
\hline (sc)GOS / TOS & $\begin{array}{l}\text { Produced from lactose by } \beta \text {-galactosidase; } \beta \text {-1,6-linked galactosyl residues (DP 2-5) linked to } \\
\text { terminal glucose unit via } \beta-1,4 \text {-bond }\end{array}$ & Coulier et al., 2009 \\
\hline$\beta-G O S$ & Produced with a novel Bifidobacterium $\beta$-galactosidase enzyme & Depeint et al., 2008 \\
\hline XOS & $\begin{array}{l}\text { Produced by partial enzymatic hydrolysis of xylan from birch wood; mixture of xylose and } \\
\text { XOS, mostly DP 2-3 }\end{array}$ & Aachary and Prapulla, 20 \\
\hline \multicolumn{3}{|l|}{ Other dietary fibres } \\
\hline Arabic gum/ acacia gum & $\begin{array}{l}\text { Produced from hardened sap of acacia tree; mixture of glycoproteins and polysaccharides, } \\
\text { mainly arabinose and galactose }\end{array}$ & Williams and Phillips, 200 \\
\hline Konjac glucomannan & $\begin{array}{l}\text { Extracted from konjac tubers; chain of D-mannose and D-glucose with a a-1,4-pyranoside } \\
\text { bond and a few acetyl groups at C- } 6 \text { position of the side chain }\end{array}$ & Yang et al., 2017 \\
\hline Beta-glucans & $\begin{array}{l}\text { Glucose molecules in long linear polymers with blocks of } 2-4 \text { glucose units linked by } \beta-(1 \rightarrow 4) \\
(70 \%) \text {, and separated by } \beta-(1 \rightarrow 3) \text { glucose links }(30 \%)\end{array}$ & Wood, 2007 \\
\hline PHGG & Isolated from guar seeds and partial enzymatic hydrolysis & Mudgil et al., 2014 \\
\hline PDX & Prepared by thermal polymerization of glucose; contains various types of glycosidic bonds & Craig et al., 1998 \\
\hline \multicolumn{3}{|l|}{ Resistant starches } \\
\hline RS1 & $\begin{array}{l}\text { Physically inaccessible or digestible resistant starch from e.g. seeds, legumes, unprocessed } \\
\text { whole grain }\end{array}$ & Homayouni et al., 2014 \\
\hline RS2 & Natural granular form (e.g. from uncooked potatoes) & \\
\hline RS3 & Retrograded starch like cooked \& cooled starchy foods & \\
\hline RS4 e.g. SCF (RM) & $\begin{array}{l}\text { Produced from wheat or corn starch by controlled dextrinization to DP } 10-30 \text { with } 1,2 \text { and } 1,3 \\
\text { glycosidic linkages; or produced by combination of heat and enzymatic treatment; wide variety } \\
\text { of structures not found in nature. May be mixtures of } a(1 \rightarrow 6), a(1 \rightarrow 4), a(1 \rightarrow 2) \text {, and } a(1 \rightarrow 3) \\
\text { glucosidic linkages }\end{array}$ & \\
\hline
\end{tabular}

\footnotetext{
${ }^{1} \mathrm{DP}=$ degree of polymerisation; FOS = fructooligosaccharides; $\mathrm{AXOS}=$ arabinoxylooligosaccharides; GOS/TOS = (trans)-galactooligosaccharides; Ic = long chain; $\mathrm{PDX}=$ polydextrose; $\mathrm{PHGG}=$ Partially hydrolysed guar gum; $\mathrm{RM}$ = resistant maltodextrin; $\mathrm{RS}=$ resistant starch; $\mathrm{SC}=$ short chain; $\mathrm{SCF}=$ soluble corn fibre; $\mathrm{XOS}=$ xylooligosaccharides.
}

Several other NDOs besides chicory FOS and scFOS are included in this review: the prebiotic galactooligosaccharides (GOS) produced on an industrial scale from milk lactose, which usually contain lactose, glucose and galactose (Torres et al., 2010); xylooligosaccharides (XOS); and arabinoxylooligosaccharides (AXOS) which are not (yet) commercially available. A 9:1 combination of GOS/ long chain inulin is widely used in infant and follow-on formulae for its prebiotic effect (Knol et al., 2005; Rinne et al., 2005; Scholtens et al., 2006). Well known dietary fibres included in this review are Arabic gum, beta-glucans, konjac glucomannan, partially hydrolysed guar gum (PHGG) and polydextrose (PDX) synthesised from glucose often of corn origin (Table 3). Commercially available resistant starches (RS), including soluble corn fibre (SCF), that exhibit dietary fibre features are also included.

Literature searches were performed using string searches with a combination of terms for dietary fibres and prebiotics with $16 \mathrm{~S}$ rRNA-based approaches to study human gut 
microbiota in the PubMed Central database (until 10 September 2019) (Supplementary Table S2). Relevant extra studies were retrieved by input from experts in the field from sources such as internal company/university databases and reading the publications found. All abstracts were read to identify relevant full publications. This is a qualitative review; the criteria for inclusion of the $16 \mathrm{~S}$ rRNA sequencing and phylogenetic array approaches were: (1) human clinical studies with single defined dietary fibres or prebiotics, or defined mixes with specified dose; (2) (randomised) human trials, blinded (unless explanation provided), at least one week duration; (3) inclusion of a placebo or control group; and (4) healthy children (not infants), adults and elderly subjects. In addition, the overweight/ obese subjects, and subjects that had various disease states such as Crohn's disease, irritable bowel syndrome (IBS), type 2 diabetes, amongst others, were also included. Studies were included whether the microbiota analysis was primary or secondary. The key outcome reported was for treatment (fibres, NDOs, prebiotics) versus placebo/control, with respect to relative abundance or counts of bacterial groups depending on the molecular technique. The impact of baseline levels of gut bacteria on outcome were discussed only secondarily, and when treatment versus placebo comparison was not available. The outcome for community-wide molecular technologies, i.e. sequencing and microarrays, which were the focus of this review are presented in Tables 4, 5 and 6, while other molecular technologies are presented in the Supplementary Tables S3, S4 and S5.

\section{Impact of prebiotics and specific fibres on the human gut microbiota}

\section{Inulin-type fructans}

A total of seventeen human studies to date used highthroughput $16 \mathrm{~S}$ rRNA-based technologies to investigate effects of inulin-type fructans on gut microbiota (Table 4). Fifteen studies used 16S rRNA gene sequencing, twelve of these studies applied the Illumina MiSeq platform, one used Ion Torrent platform, and another two studies used microarrays. These human interventions, which described the effects of mainly chicory inulin-type fructans on the colonic microbiota, confirmed the selective bifidogenic effect reported in the earlier culture-based studies, while giving less impact on other gut microbial species (Table 4).

The studies using high-throughput sequencing or microarray technologies are mainly discussed below in more detail. Many of these studies simultaneously investigated the impact on parameters of digestive or gut health. The application of the HITChip microarray enabled a comprehensive qualitative view into the effects of inulin-type fructans on a wide range of faecal microbiota. A HITChip based study on the effect of chicory FOS consumption $(20 \mathrm{~g} / \mathrm{d})$ in healthy volunteers reported an increase in the relative abundance of Bifidobacterium and a concurrent decrease of Bacteroidetes; there was no effect on alpha -diversity in this study (Tims et al., 2016). In the latter high dose chicory FOS study, fermentation increased faecal wet weight and mucin excretion (Ten Bruggencate et al., 2006). Interestingly, a shift in interactions of acetate- and lactate-utilising and butyrate-producing genera, monitored using the butyryl-CoA:acetate CoA transferase gene of the faecal ecosystem was observed for chicory FOS. This novel analysis gave insight in the cross-feeding and butyrate effect of fructans in the human colon, i.e. that inulin fermentation was associated with concurrent increase in butyrate levels, despite the fact that bifidobacteria derived fermentation products comprise acetate and lactate only. The intake of 5 and $7.5 \mathrm{~g} / \mathrm{d}$ agave fructans improved bowel habit parameters in the study subjects and increased relative abundance of faecal Actinobacteria and specifically Bifidobacterium as shown by $16 \mathrm{~S}$ rRNA amplicon sequencing (Holscher et al., 2015a). Percent of sequencing reads belonging to Bifidobacterium in control subjects in this study was $1.7 \%$, while in subjects consuming 5 and $7.5 \mathrm{~g} / \mathrm{d}$ agave inulin it was 3.2 and $4.9 \%$, respectively. Furthermore, Faecalibacterium showed a positive correlation with faecal butyrate concentration, while bifidobacteria correlated negatively with levels of faecal ammonia (Holscher et al., 2015a). In a study investigating butyrate production, subjects consumed $20 \mathrm{~g} / \mathrm{d}$ chicory inulin for 2 weeks slowly increasing the dose during the first week; this significantly increased relative abundance of various Bifidobacterium species and Anaerostipes hadrus, although it did not increase faecal butyrate levels in this short term trial, relative to resistant starch, as described below (Baxter et al., 2019). In a study with $12 \mathrm{~g} / \mathrm{d}$ of native chicory inulin studying impact on stool frequency in constipated subjects, increased relative abundance of Bifidobacterium and Anaerostipes spp. and a decreased relative abundance of Bilophila spp. were noted in the constipated subjects, as well as an improved stool frequency (Micka et al., 2017; Vandeputte et al., 2017). Another two joint studies investigating bowel habits with $10 \mathrm{~g} / \mathrm{d}$ native chicory inulin in healthy adults showed no significant differences in specific bacterial abundance nor alpha-diversity, although trends in similar directions to other studies were noted (Watson et al., 2019). Nevertheless, there was improved stool frequency when subjects had low stool frequency at baseline, and softer stool consistency reported for the treatment compared to placebo. In another study, $16 \mathrm{~g} / \mathrm{d}$ of chicory FOS was studied for its effect in subjects with orlistat-induced fat malabsorption which increases fat in the colon of the volunteers; relative abundance of Bifidobacterium sp. was increased and there were no other changes in global microbiota composition (Morales et al., 2016). The negative effects of the orlistat tended to be averted by FOS which prevented the increase of faecal calprotectin suggesting it could be beneficial in reducing colonic inflammation. 
K.S. Swanson et al.

Table 4. Effect of inulin-type fructans (ITF) on human gut microbiota composition. ${ }^{1}$

\begin{tabular}{|c|c|c|c|c|c|c|}
\hline ITF & Dose g/d & Subjects & Trial design; duration & Technology & Outcome (versus control) & Reference \\
\hline $\begin{array}{l}\text { Agave inulin in chocolate } \\
\text { chews }\end{array}$ & 5 or 7.5 & Healthy adults ( $n=29)$ & $\begin{array}{l}\mathrm{RCT}, \mathrm{DB} \text {, three period } \mathrm{CO} \text {, } \\
\text { placebo-chocolate chews with } \\
\text { no supplementation; } 21 \mathrm{~d}, 7 \\
\text { d WO }\end{array}$ & 16S rRNA sequencing (Illumina Miseq) & $\begin{array}{l}\text { Actinobacteria, Bifidobacterium } \uparrow 3 \text { - and } \\
\text { 4-fold after } 5.0 \text { and } 7.5 \mathrm{~g} \text {; Lachnobacterium, } \\
\text { Ruminococcus, Desulfovibrio } \downarrow\end{array}$ & $\begin{array}{l}\text { Holscher et al., } \\
2015 a\end{array}$ \\
\hline Chicory FOS & 20 & Healthy volunteers (n=28) & $\begin{array}{l}\mathrm{RCT}, \mathrm{DB}, \mathrm{CO} \text {, placebo sucrose; } \\
2 \text { wk intervention, } 1 \text { wk WO in } \\
\text { between }\end{array}$ & HITChip microarray & $\begin{array}{l}\text { Bifidobacterium } \uparrow \text {; Bacteroidetes } \downarrow \text {; } \\
\text { no effect on diversity }\end{array}$ & Tims et al., 2016 \\
\hline Chicory FOS & 16 & Healthy volunteers $(n=41)$ & $\begin{array}{l}\text { RCT placebo-maltodextrin; } 1 \\
\text { wk baseline, } 1 \text { wk WO, } 1 \text { wk } \\
\text { intervention, } 1 \text { wk follow-up }\end{array}$ & $\begin{array}{l}\text { 16S rRNA sequencing (Illumina Miseq), } \\
\text { RT-PCR for Bifidobacterium and } \\
\text { Lactobacillus }\end{array}$ & $\begin{array}{l}\text { Bifidobacterium } \uparrow \text {; alpha-diversity not } \\
\text { changed. }\end{array}$ & $\begin{array}{l}\text { Morales et al., } \\
2016\end{array}$ \\
\hline $\begin{array}{l}\text { Chicory FOS supplement in } \\
\text { low FODMAP diet }\end{array}$ & 14 & Healthy adults ( $\mathrm{n}=37$ ) & $\begin{array}{l}\mathrm{RCT}, \mathrm{P} \text {, placebo-maltodextrin } \\
\text { with pre and post diet } \\
\text { assessment; } 1 \text { wk, } 1 \text { wk run-in } \\
\text { period }\end{array}$ & 16S rRNA sequencing (Illumina Miseq) & $\begin{array}{l}\text { Bifidobacteria } \downarrow \text { in low FODMAP diet; } \\
\text { Ruminococcaceae } \uparrow \text { in placebo group; } \\
\text { Bifidobacteria } \uparrow \text {, Lachnospiraceae } \downarrow \text { in FOS } \\
\text { group }\end{array}$ & Sloan et al., 2018 \\
\hline Chicory inulin & 12 & Healthy volunteers $(n=44)$ & $\begin{array}{l}\mathrm{DB}, \mathrm{RCT}, \mathrm{CO} \text { placebo- } \\
\text { maltodextrin; } 4 \text { wk }\end{array}$ & 16S rRNA sequencing (Illumina Miseq) & $\begin{array}{l}\text { Bifidobacterium } \uparrow, \text { Anaerostipes } \uparrow \text {; Bilophila } \\
\downarrow ; \text { no effect on other genera; diversity } \downarrow\end{array}$ & $\begin{array}{l}\text { Vandeputte et al., } \\
2017\end{array}$ \\
\hline Chicory inulin & 8 & Type 1 diabetic children $(n=43)$ & $\begin{array}{l}\mathrm{RCT}, \mathrm{DB}, \mathrm{P} \text {, placebo } \\
\text { maltodextrin; } 3 \mathrm{mo}, 3 \mathrm{mo} \text { WO } \\
\text { at end }\end{array}$ & $\begin{array}{l}\text { 16S rRNA sequencing (Illumina Miseq), } \\
\text { qPCR for bifidobacteria }\end{array}$ & $\begin{array}{l}\text { Bifidobacterium } \uparrow \text { (B. longum), } \\
\text { Coriobacteriales } \uparrow \text { also versus baseline; } \\
\text { Bifidobacterium } \downarrow \text { after } 6 \text { mo. alpha-diversity } \\
\text { slightly } \downarrow\end{array}$ & Ho et al., 2019 \\
\hline Chicory inulin (or RS2) & 20 & $\begin{array}{l}\text { Healthy young (17-29 yr) adults } \\
(\mathrm{n}=174)\end{array}$ & $\begin{array}{l}\text { RCT, P, control accessible corn } \\
\text { starch; } 2 \text { wk over yrs }\end{array}$ & 16S rRNA sequencing (Illumina Miseq) & Bifidobacterium, Anaerostipes hadrus $\uparrow$ & Baxter et al., 2019 \\
\hline Chicory inulin & $2 \times 5$ & $\begin{array}{l}\text { Middle-age to older adults }(40-75 \\
\text { yr): Trial } A(n=10) \text {, Trial } B(n=20)\end{array}$ & $\begin{array}{l}\text { RCT, CO, placebo-maltodextrin; } \\
5 \text { wk, } 2 \text { wk wO }\end{array}$ & 16S rRNA sequencing (Illumina MiSeq) & No significant changes nor in alpha-diversity & Watson et al., 2019 \\
\hline $\begin{array}{l}\text { Chicory FOS:Ic-inulin (1:1) } \\
\text { powder in drinks }\end{array}$ & $2 \times 8$ & Obese females $(n=15)$ & $\begin{array}{l}\mathrm{RCT}, \mathrm{DB} \text {, placebo-maltodextrin; } \\
3 \mathrm{mo}\end{array}$ & $\begin{array}{l}\text { HITChip microarray, qPCR for } \\
\text { Bifidobacterium spp., Lactobacillus spp., } \\
\text { Lactobacillus acidophilus }\end{array}$ & $\begin{array}{l}\text { Bifidobacterium, Faecalibacterium prausnitzii } \\
\uparrow, \text { Bacteroides, Propionibacterium } \uparrow ; \text { qPCR: } \\
\text { Bifidobacteria, lactobacilli } \uparrow\end{array}$ & Dewulf et al., 2013 \\
\hline Chicory FOS:inulin in bar & $6+2$ & $\begin{array}{l}\text { Healthy adults with overweight/ } \\
\text { obesity }(n=25)\end{array}$ & $\begin{array}{l}\mathrm{RCT}, \mathrm{DB}, \mathrm{P} \text {; placebo-control } \\
\text { bar; } 12 \text { wk }\end{array}$ & 16S rRNA sequencing (Illumina Miseq) & Bifidobacterium $\uparrow$, alpha-diversity $\downarrow$ & Reimer et al., 2017 \\
\hline Chicory FOS:IC-inulin mix & 16 & $\begin{array}{l}\text { Healthy, low (LDF) or high dietary } \\
\text { fibre (HDF) consumers }(n=34)\end{array}$ & $\begin{array}{l}\mathrm{RCT}, \mathrm{DB}, \mathrm{CO} \text {; placebo- } \\
\text { maltodextrin; } 2 \times 3 \text { wk \& } 3 \text { wk } \\
\text { WO }\end{array}$ & 16S rRNA sequencing (Illumina Miseq) & $\begin{array}{l}\text { LDF: Bifidobacterium } \uparrow, \text { Lactobacillus } \uparrow \text {, } \\
\text { unknown genus of Ruminococcaceae } \downarrow \text {. } \\
\text { HDF: Bifidobacterium } \uparrow \text {, unknown genus } \\
\text { in Ruminococcaceae } \uparrow, \text { Faecalibacterium, } \\
\text { Coprococcus, Dorea and Ruminococcus } \downarrow \\
\text { (Lachnospiraceae family) }\end{array}$ & Healey et al., 2018 \\
\hline
\end{tabular}




\section{Table 4. Continued.}

\begin{tabular}{|c|c|c|c|c|c|c|}
\hline ITF & Dose g/d & Subjects & Trial design; duration & Technology & Outcome (versus control) & Reference \\
\hline Chicory FOS:Ic-inulin (1:1) & 8 & $\begin{array}{l}\text { Healthy overweight or obese } \\
\text { children }(n=22)\end{array}$ & $\begin{array}{l}\text { Single-centre, DB, placebo } \\
\text { maltodextrin; } 16 \text { wk }\end{array}$ & $\begin{array}{l}\text { RT-PCR and } 16 \mathrm{~S} \text { rRNA sequencing } \\
\text { (Illumina Miseq) }\end{array}$ & $\begin{array}{l}\text { Bifidobacterium } \uparrow, \text { Bacteroides vulgatus } \downarrow \\
\text { Clostridium cluster XI } \downarrow \text {, F. prausnitzii } \downarrow\end{array}$ & $\begin{array}{l}\text { Nicolucci et al., } \\
2017\end{array}$ \\
\hline Chicory Ic-inulin & $13-15$ & $\begin{array}{l}\text { Overweight men (BMl } 25-35 \mathrm{~kg} / \\
\left.\mathrm{m}^{2}\right)(\mathrm{n}=19)\end{array}$ & $\begin{array}{l}\mathrm{RCT}, \mathrm{CO}, \mathrm{DB} \text {, isoenergetic } \\
\text { control diet; } 21 \mathrm{~d}, 21 \mathrm{~d} \text { WO }\end{array}$ & 16S rRNA sequencing (Illumina MiSeq) & Bifidobacterium $\uparrow$ & Blædel et al., 2016 \\
\hline $\begin{array}{l}\text { Chicory sc-inulin \& Ic-inulin } \\
\text { mix }\end{array}$ & 6 & $\begin{array}{l}\text { 3-6 y healthy \& antibiotic-treated } \\
\text { children }(n=258)\end{array}$ & $\begin{array}{l}\text { RCT, DB, placebo-maltodextrin; } \\
24 \text { wk }\end{array}$ & $\begin{array}{l}16 \mathrm{~S} \text { rRNA sequencing (Illumina } \\
\text { multiplex); qPCR for total bacteria, } \\
\text { Bifidobacterium, Lactobacillus, } \\
\text { C. difficile, C. perfringens, and } \\
\text { Enterobacteriaceae }\end{array}$ & $\begin{array}{l}\text { qPCR: Bifidobacterium } \uparrow, \text { Lactobacillus } \\
\uparrow ; \text { sequencing: bifidobacteria } \uparrow \text {, also } \\
\text { in antibiotic-treated children; no other } \\
\text { differences reported }\end{array}$ & $\begin{array}{l}\text { Lohner et al., 2018; } \\
\text { Wang et al., 2016; } \\
\text { Soldi et al., 2019 }\end{array}$ \\
\hline $\begin{array}{l}\text { Chicory sc-inulin OR } \\
\text { sc-inulin+probiotic mix in } \\
\text { capsules }\end{array}$ & $2 \times 6$ & Asthmatic adults $(n=17)$ & $\begin{array}{l}\text { RCT, DB, CO; placebo-cellulose; } \\
7 \mathrm{~d}\end{array}$ & 16S rRNA sequencing (not specified) & $\begin{array}{l}\text { sc-inulin: Anaerostipes } \uparrow \text {, } \\
\text { Erysipelotrichaceae } \downarrow \text {; trend Bifidobacterium } \\
\uparrow \text { (significant only from baseline); sc- } \\
\text { inulin+probiotic: Bifidobacterium } \uparrow\end{array}$ & $\begin{array}{l}\text { McLoughlin et al., } \\
2019\end{array}$ \\
\hline scFOS versus GOS & 16 & Healthy adults ( $n=35$ ) & $\begin{array}{l}\mathrm{RCT}, \mathrm{DB}, \mathrm{CO} ; 1 \text { wk run in } \\
\text { period, } 14 \mathrm{~d}\end{array}$ & 16S rRNA sequencing (lon Torrent) & $\begin{array}{l}\text { FOS, GOS: Bifidobacterium } \uparrow \text {; FOS: } \\
\text { Phascolarctobacterium } \downarrow ; \text { GOS: } \\
\text { Ruminococcus } \downarrow\end{array}$ & Liu et al., 2017a \\
\hline scFOS & $2.5,5,10$ & $\begin{array}{l}\text { Healthy adults ( } n=80,20 \text { per } \\
\text { arm) }\end{array}$ & $\begin{array}{l}\mathrm{RCT}, \mathrm{DB} \text {, placebo } 10 \mathrm{~g} \\
\text { maltodextrin; } 60 \mathrm{~d} \text { run-in, } 90 \\
\text { d intervention, } 60 \mathrm{~d} \text { follow-up } \\
\text { phase }\end{array}$ & 16S rRNA sequencing (Illumina Miseq) & $\begin{array}{l}\text { Bifidobacterium } \uparrow \text { strongly \& Lactobacillus } \uparrow \\
\text { especially for } 10 \mathrm{~g} \text { dose; Faecalibacterium, } \\
\text { Ruminococcus \& Oscillospira } \uparrow \text {. Upon } \\
\text { discontinuation FOS Bifidobacterium } \downarrow \text {, } \\
\text { Oscillospira } \uparrow .\end{array}$ & Tandon et al., 2019 \\
\hline
\end{tabular}

${ }^{1} \mathrm{BMI}=$ body mass index; $\mathrm{CO}=$ crossover; $\mathrm{DB}=$ double blind; FOS = fructooligosaccharides; $\mathrm{GOS}$ = galactooligosaccharides; lc = long chain; P = parallel, qPCR = quantitative PCR; RCT = randomised controlled trial; RT-PCR = real time PCR; $\mathrm{SC}=$ short chain; $\mathrm{WO}=$ washout; $\uparrow \downarrow$, significantly increased or decreased. 
Several other interventions for fructans that monitored gut microbiota with high-throughput technologies simultaneously studied the impact on weight management or metabolic syndrome parameters. The gut microbiota of obese women was monitored using the HITChip following consumption of $16 \mathrm{~g} / \mathrm{d}$ mixture of chicory FOS and long chain inulin for 3 months (Dewulf et al., 2013). The modifications in the microbiota due to inulin were subtle, still the fructans significantly increased relative abundance of Firmicutes (mainly bacilli, and Clostridium clusters IV and XVI) and Actinobacteria, while there was a decrease in Bacteroidetes. The relative abundances of Bifidobacterium and Faecalibacterium prausnitzii also increased and this negatively correlated with serum lipopolysaccharide levels. There was a decreased relative abundance of Bacteroides, specifically Bacteroides intestinalis and Bacteroides vulgatus and Propionibacterium in the inulin group, which positively correlated with changes in body composition and glucose homeostasis; an increased proportion of Lactobacillus spp. was also detected using qPCR. In another study, analysis of faecal microbiota using the Illumina platform of overweight/obese adults showed that chicory inulintype fructans added to snack bars significantly increased relative abundance of bifidobacteria while decreased alphadiversity; several aspects of appetite control were improved (Reimer et al., 2017). Analysis of microbial functions by PICRUSt (predictive software based on the 16S rRNA composition) on the effects of inulin-type fructans on the microbiota in the latter snack bar study showed that supplementation was associated with changes in community genetic potential related to genetic information processing, metabolism of amino acids, nucleotides, terpenoids, polyketides and other pathways (Reimer et al., 2017). The third intervention studied the effect of consumption of 8 g/d of a 1:1 mix of chicory FOS and long chain-inulin in overweight and obese children, using $16 \mathrm{~S}$ sequencing and a battery of qPCR probes (Nicolucci et al., 2017). There was a significant increase in proportion of Bifidobacterium spp. while there was a decrease in B. vulgatus. Consumption of this mix was associated with significant reduction of body fat and body weight, significant decrease in serum triglycerides and serum level of interleukin 6 in these children. Another intervention with child Type I diabetes patients using the same inulin mix and dose also increased the relative abundance of Bfidobacteria at 3 months which was gone after a further 3 month washout; there were no improvements in diabetic ketoacidosis although C-peptide was significantly higher and there was a trend for improved intestinal permeability (Ho et al., 2019). Finally the impact of $16 \mathrm{~g} / \mathrm{d}$ scFOS or GOS on glycemia during oral glucose tolerance test (OGTT) and the intestinal microbiota was studied (Liu et al., 2017a). The short-term intake of 14 d, which suggested both prebiotics had an adverse effect on the glucose response, increased relative abundance of Bifidobacterium, and reduced the relative abundance of Phascolarctobacterium, Enterobacter, Turicibacter, Coprococcus and Salmonella in the FOS group.

Supplementation of $12 \mathrm{~g} / \mathrm{d}$ of sc-inulin to asthmatic adults showed increased relative abundance of Anaerostipes and a trend for that of Bifidobacterium, while Roseburia and Erysipelotrichaceae relative abundances decreased (McLoughlin et al., 2019). Post-hoc group analyses showed an improvement in asthma control and airway inflammation for the sc-inulin treatment compared to control and to a synbiotic treatment, and the changes in Anaerostipes and Roseburia were associated with these effects. Another intervention with fructans investigated the effect of a 1:1 mix of chicory FOS and long chain inulin in healthy middleaged subjects on response to influenza vaccine and on gut microbiota composition (Lomax et al., 2012). A bifidogenic effect occurred with no effect on the counts of total bacteria as shown by FISH, and there was no improvement in vaccine response. In a follow-up study, some aspects of the antibody response to vaccination were improved (Lomax et al., 2015). Recently, chain length-dependent effects of inulin-type fructans on the human systemic immune responses have been discovered, such that the long chain inulin could stimulate antibody responses in humans to a vaccine, in contrast to short chain inulin; it was hypothesised that the long chained fructan may interact with receptors in the small intestine (Vogt et al., 2017). Thus, specific chain lengths of fructans might be required for specific immune effects, and these effects might not be necessarily microbiota-mediated.

Human studies utilising earlier 16S rRNA-based methods (FISH, qPCR, band sequencing from PCR-DGGE and TRFLP) showed that fructans from sources such as chicory roots, Jerusalem or globe artichoke and agave in various food matrices generally resulted in increased levels of bifidobacteria in faeces of adults and children (Supplementary Table S3). Relatively low doses from 2.5 gram/day (g/d) could achieve this bifidogenic effect. Only two studies using FISH or qPCR showed no effect on faecal levels of bifidobacteria: one FISH study using a $15 \mathrm{~g} / \mathrm{d}$ mix of chicory FOS and long chain inulin compared to maltodextrin placebo in Crohn's disease patients (Benjamin et al., 2011), and the second study, which used $20 \mathrm{~g} / \mathrm{d}$ of a similar FOS:inulin mix in comparison to lactulose, which is also known to have a bifidogenic effect (De Preter et al., 2008).

A few studies looked more specifically into the species and strain level responses due to fructan supplementation, a majority using low throughput methods alone (Table S3 or in combination with high-throughput methods as in Table 4). These studies confirmed that consumption of chicory fructans can be associated with increased proportions of species Bifidobacterium bifidum, Bifidobacterium adolescentis, F. prausnitzii (Joossens et al., 2011; Ramirez- 
Farias et al., 2009), and Bifidobacterium longum in stools (Joossens et al., 2011). A study with agave fructans showed a significant increase specifically in B. adolescentis, B. longum, B. bifidum (Nicolucci et al., 2017), Bifidobacterium breve, and Bifidobacterium pseudolongum (Holscher et al., 2015a). In a follow-up of one human study, analysis of butyrylCoA:acetate CoA-transferase sequences using degenerate primers confirmed the increased relative abundance for F. prausnitzii for $10 \mathrm{~g}$ of chicory inulin (Louis et al., 2010; Ramirez-Farias et al., 2009).

One study concluded that the microbial and metabolic responses can vary between subjects due to differences in the initial colonic conditions including baseline levels, and metabolic activity of microbiota (bifidobacteria) (De Preter et al., 2008). Investigation of the influence of the baseline bifidobacteria levels by qPCR showed a significant correlation between baseline counts in the stools and the effect of the inulin intake, indicating that the baseline bifidobacteria levels affects the magnitude of the bifidogenic response. Habitually high dietary fibre intake was associated with stronger responses in microbiota to chicory FOS:inulin mix supplementation as suggested in one study (Healey et al., 2018). Significant increase in proportions of Faecalibacterium and decreases in Coprococcus, Dorea and Ruminococcus (Lachnospiraceae family) were noted in subjects habitually consuming high fibre diets, however, the study was limited by uneven distribution of participants in the low/high habitual fibre study groups (Healey et al., 2018).

In conclusion, studies on the impact of inulin-type fructans on the human gut microbiota using advanced $16 \mathrm{~S}$ rRNAsequencing technologies are dominated by chicory inulintype fructans and limited for other fructan types (Table 4). The majority of studies showed a bifidogenic effect for chicory inulin-type fructans, notably for B. adolescentis. In some studies, the relative abundances of Anaerostipes and lactobacilli also increased, F. prausnitzii had variable response, and sometimes the relative abundances of Bacteroidetes, Bilophila and Ruminococcus decreased. The few studies with FOS, agave and Jerusalem artichoke fructans showed increased relative abundance of bifidobacteria and sometimes lactobacilli, while sometimes the relative abundances of various other groups/ genera were reduced. Other changes in the gut microbiota were often more subtle and variable. Inulin consumption resulted in a strong (Reimer et al., 2017), modest (Vandeputte et al., 2017) or no effect (Bogovic Matijasic et al., 2016; Nicolucci et al., 2017) on global microbiota composition (alphadiversity).

Further studies are required to investigate the effect of different fructan types, fructan mixes, doses and different chain lengths on the human gut microbiota, microbial diversity and global community structure. High inter- individual variation in gut microbiota between human study subjects was also proposed as a factor that may influence the outcome of fibre effects on gut microbiota (Morales et al., 2016). As these factors are important for host intestinal and overall health, there is a need to simultaneously study broader microbial changes in response to inulin-type fructans. In addition, the effects of fructans on the different regions of the human intestinal tract should be examined in future studies.

\section{GOS, AXOS and XOS}

The studies investigating GOS, XOS and AXOS are reported in Table 5 and Supplementary Table S4. A total of eight human studies using high-throughput 16S rRNA-based technologies, including two with phylochips, investigated effect of GOS on human gut microbiota (Table 5). Initially $16 \mathrm{~S}$ sequencing was used to gain a community wide perspective of the impact of increasing doses $(2.5,5$, and $10 \mathrm{~g} / \mathrm{d}$ ) of GOS on the faecal microbiota of healthy subjects for 14 weeks (Davis et al., 2011); GOS led to five- to tenfold increases in bifidobacteria in half of the subjects and the effect was dose-dependent. Another study that used pyrosequencing and $16 \mathrm{~S}$ rRNA species-specific primers showed that supplementation with a highly purified GOS was also associated with higher relative abundance of Bifidobacterium (average relative abundance increased from 0.001 at day (d) 0 to 0.007 at d 36), specifically of $B$. adolescentis (45 to 8,212-fold increase), B. longum (42 to 108-fold increase), Bifidobacterium catenulatum (25 to 1,874-fold increase), B. breve (average 46-fold increase as detected by the GroEL probe), Bifidobacterium dentium (Azcarate-Peril et al., 2017) and other Bifidobacterium operational taxonomic unit phylotypes. Bifidobacteria effects were dose-dependent with no effect at 2.5 but increasing effect at 5 and $10 \mathrm{~g} / \mathrm{d}$ (Davis et al., 2011). In the latter two studies, F. prausnitzii was stimulated by GOS intake at 5 and $15 \mathrm{~g} / \mathrm{d}$ which was also occasionally observed for inulin-type fructans (Azcarate-Peril et al., 2017; Davis et al., 2011); additionally, the relative abundances of Lactobacillus, an unidentified genera of the family Christensenellaceae (Azcarate-Peril et al., 2017) and Coprococcus comes were higher due to GOS intake (Davis et al., 2010, 2011). After the washout period, it was observed that relative abundance of bifidobacteria amongst other groups was reduced, as expected (Azcarate-Peril et al., 2017; Liu et al., 2017a).

A few human studies investigated GOS in terms of gut health aspects. GOS had no synergistic beneficial effect in the synbiotic application with the probiotic strains B. adolescentis IVS-1 and Bifidobacterium lactis BB12 (Krumbeck et al., 2018); the relative abundance of Lachnobacterium decreased upon GOS intervention (Krumbeck et al., 2018). GOS showed a beneficial effect on recovery of the intestinal bifidobacteria though not 
K.S. Swanson et al.

Table 5. Effect of arabinoxylan-oligosaccharides (AXOS), galactooligosaccharides (GOS) and xylooligosaccharides (XOS) on human gut microbiota composition. ${ }^{1}$

\begin{tabular}{|c|c|c|c|c|c|c|}
\hline Type & Dose g/d & Subjects & Trial design and duration & Technology & Outcome (versus control) & Reference \\
\hline AXOS & 10.4 & $\begin{array}{l}\text { Overweight, obese subjects (25- } \\
\left.40 \mathrm{~kg} / \mathrm{m}^{2}\right)(\mathrm{n}=30)\end{array}$ & RT, CO, no placebo; 4 wk, 4 k WO 4 wk & $\begin{array}{l}\text { Shot-gun sequencing } \\
\text { (HiSeq2500 platform) }\end{array}$ & $\begin{array}{l}\text { Compared to baseline only: Actinobacteria } \\
\uparrow, \text { Bifidobacteriaceae } \uparrow \text {, Bifidobacterium } \uparrow, \\
\text { Ruminococcus gnavus } \uparrow, \text { Lachnospiraceae } \\
\text { groups } \uparrow \text {, Prevotella } \uparrow, \text { Rikenella } \downarrow \text {, } \\
\text { Parabacteroides } \downarrow \text {, Paraprevotella } \downarrow \text { species }\end{array}$ & $\begin{array}{l}\text { Benítez-Páez et al., } \\
2019\end{array}$ \\
\hline $\begin{array}{l}\text { GOS }(75 \% \text { w/w; } 59 \% \\
\text { GOS; } 21 \% \text { lac, } 19 \% \text { glu, } \\
1 \% \text { gal) }\end{array}$ & $2.5 \times 3(7.5)$ & Healthy volunteers $(n=12)$ & $\begin{array}{l}\text { RCT, DB, P placebo-maltodextrin } 12 d \\
\text { total: } 5 \text { d AMX + GOS ( } n=6) / \text { placebo } \\
(n=6) \text {, followed by } 7 \mathrm{~d} \text { no AMX }\end{array}$ & $\begin{array}{l}\text { Intestinal-chip/ microarray, } \\
\text { qPCR for total bacteria and } \\
\text { Bifidobacterium spp. }\end{array}$ & $\begin{array}{l}\text { GOS with antibiotic treatment } \uparrow \text { bifidobacteria; } \\
\text { faster recovery to normal with GOS }\end{array}$ & Ladirat et al., 2014 \\
\hline $\begin{array}{l}\text { GOS (69\%; } 23 \% \text { lac, } \\
22.8 \% \text { lac, } 4.7 \% \text { glu })\end{array}$ & 15 & $\begin{array}{l}\text { Overweight or obese, pre- } \\
\text { diabetic }(n=44)\end{array}$ & $\begin{array}{l}\mathrm{RCT}, \mathrm{DB}, \mathrm{P} ; 12 \text { wk; placebo- } \\
\text { maltodextrin }\end{array}$ & HITChip microarray & Bifidobacterium $\uparrow$ & Canfora et al., 2017 \\
\hline $\begin{array}{l}\text { GOS }(72,5 \% ; 23 \% \\
\text { lac, } 5 \% \text { glu + gal), } \\
\text { GOS+Bifidobacterium } \\
\text { adolescentis IVS-1 + } \\
\text { Bifidobacterium lactis } \\
\text { BB-12 }\end{array}$ & 5 & Obese adults $(n=114)$ & RCT, DB, P, placebo-lactose; 3 wk & $\begin{array}{l}\text { 16S rRNA sequencing } \\
\text { (Illumina Miseq); qPCR } \\
\text { for Bifidobacterium, } B \text {. } \\
\text { adolescentis }\end{array}$ & $\begin{array}{l}\text { Bifidobacterium } \uparrow \text { in GOS: IVS-1 induced higher } \\
\text { levels of bifidobacteria than Bb12; no functional } \\
\text { synergism when used as synbiotic }\end{array}$ & $\begin{array}{l}\text { Krumbeck et al., } \\
2018\end{array}$ \\
\hline $\operatorname{GOS}(80 \%)$ & 5.5 & T2D men $(n=29)$ & RCT, P; placebo-maltodextrin; 12 wk & $\begin{array}{l}\text { 16S rRNA sequencing } \\
\text { (GS FLX Titanium } \\
\text { platform), qPCR for total } \\
\text { bacteria, Bifidobacterium, } \\
\text { Roseburia, Lactobacillus, } \\
\text { Enterobacteriaceae, } \\
\text { Clostridium leptum, } \\
\text { Clostridium coccoides } \\
\text { groups }\end{array}$ & $\begin{array}{l}\text { No significant changes on bacterial abundances } \\
\text { compared with placebo; trend } \uparrow \text { Bifidobacterium }\end{array}$ & $\begin{array}{l}\text { Pedersen et al., } \\
2016\end{array}$ \\
\hline $\begin{array}{l}\text { GOS }(80 \%) \text { in gluten and } \\
\text { casein-free diets, and in } \\
\text { unrestricted diet }\end{array}$ & 1.44 & Autistic children (4-11 y) (n=30) & RCT, DB, P, placebo-maltodextrin; 6 wk & $\begin{array}{l}\text { 16S rRNA sequencing } \\
\text { (Illumina Miseq); FISH } \\
\text { for total bacteria and } \\
\text { Bifidobacterium spp. }\end{array}$ & $\begin{array}{l}\text { Bifidobacterium longum } \uparrow \text { in exclusion diet + } \\
\text { GOS group. Positive association of GOS with } \\
\text { Bifidobacterium spp., Ruminococcus spp., } \\
\text { Lachnospiraceae family (Coprococcus spp., } \\
\text { Dorea formicigenerans, Oribacterium spp.), } \\
\text { Eubacterium dolchum, TM7-3 family and } \\
\text { Mogibacteriaceae }\end{array}$ & Grimaldi et al., 2018 \\
\hline
\end{tabular}


Table 5. Continued.

\begin{tabular}{|c|c|c|c|c|c|c|}
\hline Type & Dose g/d & Subjects & Trial design and duration & Technology & Outcome (versus control) & Reference \\
\hline $\begin{array}{l}\text { GOS }(91.8 \% ; 7 \% \text { lac, } 1 \% \\
\text { glu, } 0.5 \% \text { gal) in caramel } \\
\text { chews }\end{array}$ & $\begin{array}{l}2.5,5.0 \\
\text { or } 10\end{array}$ & Healthy volunteers $(n=18)$ & $\begin{array}{l}\text { Single blinded (randomisation not } \\
\text { specified); } 2 \text { wk baseline, } 3 \text { wk for each } \\
\text { dose, no WO between; } 2 \text { wk final WO }\end{array}$ & $\begin{array}{l}\text { 16S rRNA pyrosequencing } \\
(454)\end{array}$ & $\begin{array}{l}0,2.5 \mathrm{~g} \text { dose: no change. } 5 \text { \& } 10 \mathrm{~g} \text { doses: } \\
\text { Bifidobacteriaceae, Bacteroidaceae } \uparrow ; B \text {. } \\
\text { adolescentis, B. longum, Bifidobacterium } \\
\text { catenulatum } \uparrow . \text { At } 5 \mathrm{~g} \text { only: Faecalibacterium } \\
\text { prausnitzii } \uparrow ; \text { At } 10 \mathrm{~g} \text { only: Coprococcus } \downarrow\end{array}$ & Davis et al., 2011 \\
\hline $\begin{array}{l}\text { GOS/RP-G28 (purified } \\
\text { scGOS >95\%) }\end{array}$ & 15 & $\begin{array}{l}\text { Lactose-intolerant subjects } \\
(n=52)\end{array}$ & $\begin{array}{l}\text { RCT, DB, P, multi-site; placebo-corn } \\
\text { syrup; } 30 \mathrm{~d}\end{array}$ & $\begin{array}{l}\text { 16S rRNA pyrosequencing } \\
\text { (454) on treatment \& qPCR } \\
\text { for Bifidobacterium species; } \\
\text { T-RFLP on placebo }\end{array}$ & $\begin{array}{l}\text { From baseline bifidobacteria } \uparrow 27 / 30 \text { subjects } \\
(90 \%) ; \text { qPCR: lactose-fermenting Bifidobacterium, } \\
\text { Faecalibacterium and Lactobacillus } \uparrow\end{array}$ & $\begin{array}{l}\text { Azcarate-Peril et al., } \\
2017\end{array}$ \\
\hline $\begin{array}{l}\text { GOS ( } 95 \% \text { purity) versus } \\
\text { scFOS }\end{array}$ & 16 & Healthy adults ( $n=35$ ) & $\mathrm{RCT}, \mathrm{DB}, \mathrm{CO} ; 1$ wk run in period, $14 \mathrm{~d}$ & $\begin{array}{l}\text { 16S rRNA sequencing (lon } \\
\text { Torrent) }\end{array}$ & $\begin{array}{l}\text { GOS, FOS: Bifidobacterium } \uparrow ; \text { GOS: } \\
\text { Ruminococcus } \downarrow \text {; FOS: Phascolarctobacterium } \downarrow\end{array}$ & Liu et al., 2017a \\
\hline XOS in capsules & 1.4 or 2.8 & Healthy adults ( $n=32$ ) & $\begin{array}{l}\text { RCT, DB, placebo-maltodextrin; } 2 \text { wk } \\
\text { run in, } 8 \text { wk intervention, } 2 \text { wk WO }\end{array}$ & $\begin{array}{l}16 \mathrm{~S} \text { rRNA } \\
\text { pyrosequencing (GS } \\
\text { FLX Titanium); Culturing: } \\
\text { Enterobacteriaceae, } \\
\text { Bacteroides fragilis group, } \\
\text { Clostridium, Bifidobacterium, } \\
\text { Lactobacillus }\end{array}$ & $\begin{array}{l}\text { No change alpha-diversity; Faecalibacterium and } \\
\text { Akkermansia } \uparrow \text { at specific wk; Bifidobacterium } \uparrow \\
\text { on both doses by culturing only at } 8 \text { and } 10 \text { wk, } \\
\text { anaerobic counts } \uparrow \text { and } B \text {. fragilis counts } \uparrow \text { at } \\
2.8 \mathrm{~g}\end{array}$ & Finegold et al., 2014 \\
\hline XOS in capsules & 2 & $\begin{array}{l}\text { Healthy }(n=16) \text { and pre-T2D } \\
\text { subjects }(n=13)\end{array}$ & $\mathrm{RCT}$, P, placebo-maltodextrin; 8 wk & $\begin{array}{l}16 \text { rRNA sequencing } \\
\text { (Illumina MiSeq) }\end{array}$ & $\begin{array}{l}\text { Significant differences in healthy \& pre- } \\
\text { DM microbiota composition. In pre-T2D: } \downarrow \\
\text { Howardella, Slackia, Enterorhabdus. No change } \\
\text { in Bifidobacterium (genus and } 3 \text { spp.) in healthy } \\
\text { volunteers }\end{array}$ & Yang et al., 2015 \\
\hline
\end{tabular}


significantly, however there was a significant increase in butyrate levels after antibiotic treatment in healthy adults (Ladirat et al., 2014). A higher dose of highly purified GOS (>95\% purity; $15 \mathrm{~g} / \mathrm{d}$ ) consumed by lactose-intolerant individuals significantly shifted subject's microbiota composition, increased abundance of lactose-fermenting Bifidobacterium, Faecalibacterium, and Lactobacillus and had a positive effect on lactose digestion and tolerance (Azcarate-Peril et al., 2017). In fact, the higher relative abundance of Bifidobacterium was negatively correlated with cramping and pain in lactose-intolerant subjects. Furthermore, PICRUSt analysis was included in this study and revealed changes in the community genetic potential with a gradual increase in abundance of predicted enzymes involved in GOS metabolism during GOS intake. In a recent study GOS intervention was positively correlated with improvements in anti-social behaviour in autistic children, and there was significant increase in abundance of Lachnospiraceae family; bifidobacteria relative abundance had also increased though not significantly (Grimaldi et al., 2018).

There were three studies investigating GOS intake with overweight, type-2- or pre-diabetic subjects. In a study on GOS effects on microbiota of type 2 diabetic patients, supplementation at $5.5 \mathrm{~g} / \mathrm{d}$ was not associated with microbial community shifts and the bifidogenic effect did not reach significance in this cohort, possibly due to interaction with the medication (Metformin) and the high heterogeneity of human type 2 diabetes (Pedersen et al., 2016). In addition, there was a negative correlation between abundance of family Veillonellaceae after GOS intake. The GOS supplementation had no significant effects on clinical outcomes such as intestinal permeability and glucose tolerance (Pedersen et al., 2016). In a second study, supplementation of diets of obese, pre-diabetic subjects with $15 \mathrm{~g} / \mathrm{d}$ GOS for 12 weeks increased the abundance of Bifidobacterium species in faeces by 5 -fold, while microbial richness or diversity were not changed, as measured by HITChip (Canfora et al., 2017); there were no significant changes in insulin sensitivity or related substrate and energy metabolism in the subjects. Finally, short-term intake of 16 $\mathrm{g} / \mathrm{d}$ GOS increased relative abundance of Bifidobacterium and decreased relative abundances of Ruminococcus, Dehalobacterium, Synergistes and Holdemania some of which are butyrate-producing microbes, and it was speculated that this may have played a role in the adverse effect on glucose metabolism, as measured by fasting glucose levels (Liu et al., 2017a).

Two studies to date utilised 16S rRNA sequencing to measure the microbial effects of XOS. XOS supplementation at 1.4 or $2.8 \mathrm{~g} / \mathrm{d}$ for 10 weeks showed no notable shifts in community diversity, though for the $2.8 \mathrm{~g} / \mathrm{d}$ dose increases in proportions of $F$. prausnitzii and Akkermansia at different weeks were detected (Finegold et al., 2014). It is noteworthy that bifidobacteria, total anaerobes, and Bacteroides fragilis were higher in the 1.4 and $2.8 \mathrm{~g} / \mathrm{d}$ treatments, respectively, as estimated by plate culturing. It was suggested that lack of significant effects of XOS on the microbiota by $16 \mathrm{~S}$ rRNA using the 454 pyrosequencing platform might be due to lack of primer specificity for bifidobacteria (Hooda et al., 2012). It is noteworthy that the total anaerobes cultured would probably be much lower than actually present in this study, and therefore the bifidobacteria increase could be overestimated by culturing. Indeed, in another study, impact of $2 \mathrm{~g} / \mathrm{d}$ of XOS was evaluated for 8 weeks in healthy and prediabetic subjects using a different sequencing platform and primers, and this also did not show a bifidogenic effect, although it did induce shifts in a number of other genera (Yang et al., 2015) (Table 4).

Recently, the impact of an AXOS-enriched diet on microbiota of overweight and obese subjects with indices of metabolic syndrome using metagenome sequencing indicated increased relative abundance of Bifidobacterium, Ruminococcus, and Lachnospiraceae compared to baseline after a 4-week intervention (Benítez-Páez et al., 2019). Metagenome analysis showed increases in the presence of bacterial genes involved in vitamin/cofactor production, glycan metabolism, and neurotransmitter biosynthesis after the AXOS intake; together with the additional lipidomics and metabolomics in this study, it appeared that multiple effects of AXOS supported reversing the glucose homeostasis impairment in the subjects. Five other human studies with AXOS utilising FISH or RT-PCR also showed the bifidogenic effect or a trend, and sometimes effects on other groups (Supplementary Table S4). The effect of AXOS varied with respect to other taxa and depended on whether AXOS was supplemented in bread (Walton et al., 2012), or added to drinks (Francois et al., 2012). The inconsistent results might be due to structural differences between AXOS, as it is known from animal studies that the structure of AXOS, i.e. the ratio between arabinose and xylose, impacts its fermentation behaviour (Van Craeyveld et al., 2008). Clearly, further community-wide phylogenetic studies are required for both XOS and AXOS.

In conclusion, in several 16S rRNA-based studies GOS clearly stimulated a strong selective bifidogenic effect and increased relative abundances of few other groups, similar to inulin. Culturing or FISH studies suggest bifidogenic effects also for XOS and AXOS at least. However, there is insufficient data generated yet for XOS and AXOS using sequencing technologies. Thus, it appears too early to draw conclusions on relationships between structures of the latter two fibres and their impact on composition of the human gut microbiota. 


\section{Resistant starches, polydextrose, beta-glucans, Arabic gum, konjac glucomannan and PHGG}

A large number of studies to date focused on the microbiota modulating effects of glucose-based carbohydrates, namely resistant starches RS2, RS3, RS4 (resistant maltodextrin (RM; or SCF), and polydextrose (PDX), mainly using highthroughput methods (Tables 6 and Supplementary S5).

Five human studies using sequencing investigated RS2 type (high amylose) maize starch which indicated quite some variable changes in abundances of gut bacterial groups, also in comparison to RS4 (Table 6). In order to systematically develop dietary strategies based on RS that modulate the human gut microbiota, the effect of two types of RS, RS2 and RS4, was studied (Martinez et al., 2010). Interestingly, the two different RS types had different effects on the gut community structure; RS4, but not RS2 induced phylum-level changes, significantly increasing proportions of Actinobacteria and Bacteroidetes while decreasing Firmicutes (Martinez et al., 2010; Upadhyaya et al., 2016). On the other hand, RS2 had an opposite effect, showing an increase in the relative abundance of Firmicutes while decreasing the relative abundance of Bacteroidetes (Martinez et al., 2010). At the species level, RS4 showed increased relative abundance of B. adolescentis (in some individuals quite significantly) and Parabacteroides distasonis, while RS2 significantly raised the proportions of $R$. bromii and E. rectale when compared to RS4. The crossover design revealed that the microbiota responses to $\mathrm{RS}$ and their levels varied between individuals, and that the effects were reversible (Martinez et al., 2010). In a study to investigate the potential of RS to reduce intestinal inflammation, RS2 at $8.5 \mathrm{~g} / \mathrm{d}$ was supplemented to the diet of stunted Malawian children (Ordiz et al., 2015). This increased the relative abundance of Actinobacteria and decreased that of Firmicutes, however, there was no change in faecal calprotectin suggesting that RS did not reduce gut inflammation in this setting. The impact of $40 \mathrm{~g} / \mathrm{d}$ of high amylose maize RS2 on adult microbiota, showed mainly increased relative abundance of Ruminococcaceae while many other genera decreased; notably a higher relative abundance of the genus Streptococcus was associated with an increase in postprandial hormones, and lower relative abundances of Ruminococcus torques, Eubacterium hallii and Eubacterium eligens groups with reduced abdominal adiposity (Zhang et al., 2019).

Another five human studies investigated effects of RS2 from potato starch which showed numerous changes to bacterial groups in the gut microbiota (Table 6). The most in-depth study on RS2 used a combination of -omics approaches, including $16 \mathrm{~S}$ rRNA gene sequencing, metaproteomics and metabolomics, to gain a broader understanding of microbehost interplay in response to RS2 supplementation (Maier et al., 2017). Shotgun metagenomics applied to determine the impact of these fibres on the functional capacity of the gut microbiota showed shifts in bacterial gene abundances for genes associated with carbohydrate, amino acid, and lipid metabolism, as well as metabolism of cofactors and vitamins. In a follow up study for this trial, pathway-based metagenomics was performed on a subset of individuals samples to obtain more insight into the functional aspects (Vital et al., 2018). The outcome indicated a framework whereby primary degradation of RS2 was dominated by Firmicutes, particularly with Ruminococcus bromii, providing SCFAs, notably increased acetate levels which supported the growth of various butyrate producers; $\mathrm{H}_{2}$ scavenging sulphite reducers and acetogens concurrently increased. Individual responses of gut microbiota were observed in this study to RS2. Other sequencing studies with RS2 in adults were associated with increased relative abundance of Bifidobacterium and often R. bromii, besides other bacterial group changes (Alfa et al., 2018; Flowers et al., 2019; Venkataraman et al., 2016).

RS2 from either potato (28-34 g/d) or maize (20-24 g/d) were compared in one human study for their effect on faecal butyrate in a 2 week intervention while slowly increasing the dose during the first week (Baxter et al., 2019). The potato RS2 increased relative abundance of some bifidobacterial species, R. bromii and Clostridium chartatabidum in some individuals, while maize RS2 increased proportions of certain clostridia and $R$. bromii, though it had no effect on bifidobacteria. Those individuals microbiomes that responded with increased relative abundances of $R$. bromii and $C$. chartatabidum for potato RS significantly increased butyrate production on the short term (Baxter et al., 2019).

The effect of a diet enriched with RS2 from both potato and maize with arabinoxylan was studied in adults with metabolic syndrome who consumed a low fibre diet and compared to the low-fibre diet as control (Hald et al., 2016). This RS2-diet significantly increased relative abundance of Bifidobacterium, and decreased abundances of several other genera while alpha-diversity decreased. SCFA levels were higher in the stools of the subjects with the RS2-enriched diet while BCFAs (branched chain fatty acids) indicative of protein fermentation were lower.

The study on the impact of RS3 or non-starch polysaccharides (NSPs) on the faecal microbiota of overweight men showed that the RS3 diet was associated with increased relative abundance of $R$. bromii and E. rectale in most volunteers as compared to those consuming the NSP diet (Walker et al., 2011). There was marked interindividual variation as $>60 \%$ of $\mathrm{RS}$ remained unfermented in two volunteers on the RS diet, compared to $<4 \%$ in the other 12 volunteers; these two individuals also showed low levels of $R$. bromii as assessed by qPCR suggesting involvement of this species in RS3 metabolism. In a follow up study of the same trial, the composition and diversity of the faecal 
K.S. Swanson et al.

Table 6. Effect of $\beta$-glucan, partially hydrolysed guar gum, resistant starches and polydextrose on human gut microbiota composition. ${ }^{1}$

\begin{tabular}{|c|c|c|c|c|c|c|}
\hline Type & Dose $\mathrm{g} / \mathrm{d}$ & Subjects & Trial design and duration & Technology & Outcome (versus control) & Reference \\
\hline ß-glucan (barley) & $\begin{array}{l}3 \text { HMW, } \\
3 \text { LMW, } 5 \\
\text { LMW }\end{array}$ & $\begin{array}{l}\text { Mildly hyper- } \\
\text { cholesterolemic adults, } \\
\text { TC } 5-8 \& \text { LDL-C } 2.7-5.0 \\
\mathrm{mmol} / /, \mathrm{BMI} 20-24 \mathrm{~kg} / \mathrm{m}^{2} \\
(\mathrm{n}=19)\end{array}$ & $\begin{array}{l}\mathrm{RCT}, \mathrm{CO} \text {, placebo-wheat or rice; } 5 \text { wk, } \\
4 \text { wk WO }\end{array}$ & $\begin{array}{l}\text { 16S rRNA sequencing } \\
\text { (Illumina) }\end{array}$ & $\begin{array}{l}\text { No change in alpha-diversity. } 3 \mathrm{~g} \mathrm{HMW} \text { : phyla } \\
\text { Bacteroidetes } \uparrow \text {, Firmicutes } \downarrow \text {; Bacteroides, Prevotella } \uparrow \text {, } \\
\text { Streptococcus, Dorea } \downarrow ; 5 \mathrm{~g} \text { LMW, } 3 \mathrm{~g} \text { LMW: no effects }\end{array}$ & Wang et al., 2016 \\
\hline PHGG & 6 & $\begin{array}{l}\text { Children with ASD (4-9 yr) } \\
(n=13)\end{array}$ & Non-randomised & $\begin{array}{l}16 S \text { rRNA sequencing } \\
\text { (Illumina MiSeq) }\end{array}$ & $\begin{array}{l}\text { Numerous changes: e.g. Blautia, Acidaminococcus } \uparrow \text {, } \\
\text { Streptococcus, Odoribacter and Eubacterium (family } \\
\text { Erysipelotrichaceae) } \downarrow \text {. alpha-diversity } \downarrow\end{array}$ & Inoue et al., 2019 \\
\hline $\begin{array}{l}\text { RS2 (maize) or RS4 in } \\
\text { crackers }\end{array}$ & 33 & Healthy adults $(n=10)$ & $\begin{array}{l}\mathrm{DB}, \mathrm{CO} \text {, placebo-native wheat starch; } \\
2 \text { wk run in, } 3 \text { wk interventions, with } 2 \\
\text { wk WO in between, } 2 \text { wk final wO }\end{array}$ & $\begin{array}{l}\text { 16S rRNA pyrosequencing } \\
\text { (454); PCR-DGGE, qPCR } \\
\text { for Bifidobacterium spp. }\end{array}$ & $\begin{array}{l}\text { RS2: phyla Firmicutes } \uparrow \text {; family Ruminococcaceae } \\
\uparrow \text {; Dorea } \downarrow \text {. RS4: phyla Actinobacteria, Bacteroidetes } \\
\uparrow, \text { Firmicutes } \downarrow \text {; family Bifidobacteriaceae, } \\
\text { Porphyromonadaceae } \uparrow, \text { Ruminococcaceae } \\
\text { Erysipelotrichaceae } \downarrow \text {; genus Bifidobacterium, } \\
\text { Parabacteroides } \uparrow, \text { Faecalibacterium, Dorea } \downarrow\end{array}$ & Martinez et al., 2010 \\
\hline $\begin{array}{l}\text { RS2 (high amylose } \\
\text { maize) }\end{array}$ & 8.5 & $\begin{array}{l}\text { Stunted Malawi children } \\
(3-5 \mathrm{yr})(\mathrm{n}=18)\end{array}$ & $\begin{array}{l}\text { Non-randomised; comparison with } \\
\text { usual diet }\end{array}$ & $\begin{array}{l}16 S \text { rRNA sequencing } \\
\text { (Illumina HiSeq) }\end{array}$ & $\begin{array}{l}\text { On RS: phyla Actinobacteria } \uparrow \text {, Firmicutes } \downarrow \text {; families } \\
\text { Coriobacteriaceae } \uparrow \text { and Lachnospiraceae } \downarrow \text {; genus: } \\
\text { Lactobacillus } \uparrow \text {; Roseburia, Blautia, Lachnospiraceae } \\
\text { unclassified, Clostridium XIVa, Oscillibacter, } \\
\text { Butyricicoccus, and Lachnospiraceae incertae sedis all } \downarrow\end{array}$ & Ordiz et al., 2015 \\
\hline $\begin{array}{l}\text { RS2 (high amylose } \\
\text { maize) }\end{array}$ & 40 & $\begin{array}{l}\text { Healthy adults (18-55 yr) } \\
(n=19)\end{array}$ & $\begin{array}{l}\text { RCT, DB, CO; placebo starch; } 4 \text { wk, } \\
4 \text { wk WO }\end{array}$ & $\begin{array}{l}16 \mathrm{~S} \text { rRNA sequencing } \\
\text { (Titanium) }\end{array}$ & $\begin{array}{l}\text { Ruminococcaceae } \uparrow ; 15 \text { genera } \downarrow \text { including } \\
\text { members of Anaerostipes, Bacteroides, Blautia, } \\
\text { Holdemanella, Coprococcus, Lachnoclostridium, } \\
\text { Lachnospiraceae, Erysipelotrichaceae, Paraprevotella, } \\
\text { Phascolarctobacterium, Ruminiclostridium \& } \\
\text { Ruminococcaceae; no change in alpha-diversity }\end{array}$ & Zhang et al., 2019 \\
\hline $\begin{array}{l}\text { RS2 (high-amylose } \\
\text { maize, raw potato } \\
\text { starch) + AX-enriched } \\
\text { diet }\end{array}$ & 20.7 & $\begin{array}{l}\text { Adults with metabolic } \\
\text { syndrome }(n=19)\end{array}$ & $\begin{array}{l}\text { RCT, CO, blinding not possible, } \\
\text { control low fibre diet; } 4 \text { wk }\end{array}$ & $\begin{array}{l}\text { 16S rRNA sequencing } \\
\text { (Illumina MiSeq) }\end{array}$ & $\begin{array}{l}\text { Bifidobacterium } \uparrow \text {; numerous other genera } \downarrow \text {, e.g. } \\
\text { Bacteroides, Lachnospira, Ruminococcus, Anaerostipes, } \\
\text { Butyricimonas; alpha-diversity } \downarrow\end{array}$ & Hald et al., 2016 \\
\hline $\begin{array}{l}\text { RS2 (high amylose) in } \\
\text { biscuits }\end{array}$ & 20,25 & $\begin{array}{l}\text { End-stage renal disease } \\
\text { patients }(n=20)\end{array}$ & $\begin{array}{l}\mathrm{RCT}, \mathrm{P}, \text { control biscuits with regular } \\
\text { flour; } 20 \text { and } 25 \mathrm{~g} / \mathrm{d} \text { in mo } 1 \text { and } 2 \text {, } \\
\text { respectively }\end{array}$ & $\begin{array}{l}16 S \text { rRNA sequencing } \\
\text { (Illumina MiSeq) }\end{array}$ & Faecalibacterium genus $\uparrow$ & Laffin et al., 2019 \\
\hline $\begin{array}{l}\text { RS2 potato (RSP) or } \\
\text { maize (RSM) }\end{array}$ & $\begin{array}{l}28-34 \\
20-24\end{array}$ & $\begin{array}{l}\text { Healthy young }(17-29 \mathrm{yr}) \\
\text { adults }(n=174)\end{array}$ & $\begin{array}{l}R C T, P \text {, control accessible corn starch; } \\
2 \text { wk to over few yrs }\end{array}$ & $\begin{array}{l}\text { 16S rRNA sequencing } \\
\text { (Illumina Miseq) }\end{array}$ & $\begin{array}{l}\text { RPS: Bifidobacterium faecale/ adolescentis/ stercoris } \uparrow, \\
\text { R. bromii, Clostridium type } \uparrow \text { in subset; RSM: } R \text {. bromii } \uparrow\end{array}$ & Baxter et al., 2019 \\
\hline
\end{tabular}




\section{Table 6. Continued.}

\begin{tabular}{|c|c|c|c|c|c|c|}
\hline Type & Dose $\mathrm{g} / \mathrm{d}$ & Subjects & Trial design and duration & Technology & Outcome (versus control) & Reference \\
\hline $\begin{array}{l}\mathrm{RS} 2 \text { (Solanum } \\
\text { tuberosum extract) }\end{array}$ & 30 & $\begin{array}{l}\text { Elderly }(n=20) \text { and mid- } \\
\text { aged adults }(n=20)\end{array}$ & $\begin{array}{l}\text { RCT, DB, P; placebo corn starch; } 3 \\
\text { mo }\end{array}$ & $\begin{array}{l}\text { 16S rRNA sequencing } \\
\text { (Illumina MiSeq) }\end{array}$ & $\begin{array}{l}\text { Bifidobacterium } \uparrow \text {; in elderly only Proteobacteria } \\
\text { (Escherichia coli/Shigella) } \downarrow \text {, Prevotella } \uparrow \text {, Alistipes } \uparrow \text {, } \\
\text { Desulfovibrio } \uparrow, \text { Mogibacterium } \uparrow, \text { Sporobacter } \uparrow \text {; in mid } \\
\text { aged only Olsenella } \uparrow \text {, Coprobacillus } \downarrow \text {, Lactobacilllus } \downarrow\end{array}$ & Alfa et al., 2018 \\
\hline $\begin{array}{l}\text { RS2 (Solanum } \\
\text { tuberosum tuber) }\end{array}$ & $\begin{array}{l}\text { HRS: } 66 \text { or } \\
4 ; \text { LRS: } 48 \\
\text { or } 3\end{array}$ & $\begin{array}{l}\text { Insulin resistant adults on } \\
\text { low }(n=23) \text { or high }(n=16) \\
\text { carbohydrate diets; } n=12 \\
\text { for meta-genomics of } \\
\text { LC arm }\end{array}$ & $\begin{array}{l}\text { RCT, CO, time series study with } \\
\text { LRS versus HRS; } 2 \text { wk run-in, } 2 \text { wk } \\
\text { intervention, } 2 \text { wk WO }\end{array}$ & $\begin{array}{l}16 \text { S rRNA sequencing } \\
\text { (Illumina HiSeq 2000); } \\
\text { metagenomics }\end{array}$ & $\begin{array}{l}\text { Firmicutes } \uparrow, \text { Bacteroidetes } \downarrow \text { (Faecalibacterium } \\
\text { prausnitzii, Prevotellaceae, Ruminococcus, Eubacterium } \\
\text { rectale, Roseburia faecis, Akkermansia muciniphila } \uparrow \text { ); } \\
\text { metagenomics: see text }\end{array}$ & $\begin{array}{l}\text { Maier et al., 2017; } \\
\text { Vital et al., } 2018\end{array}$ \\
\hline $\begin{array}{l}\text { RS2 (unmodified potato } \\
\text { starch) }\end{array}$ & $\begin{array}{l}12,24,48 \\
(50 \% \text { RS2) }\end{array}$ & $\begin{array}{l}\text { Healthy young adults } \\
(\mathrm{n}=20)\end{array}$ & $\begin{array}{l}\text { Non-randomised; control-habitual } \\
\text { diet; gradual increase for } 3 \mathrm{~d} \text {, then } 7 \\
\text { d total dose }\end{array}$ & $\begin{array}{l}16 S \text { rRNA sequencing } \\
\text { (Illumina MiSeq) }\end{array}$ & $\begin{array}{l}\text { Individuals classified into enhanced, high, \& low ( } \mathrm{n}=11 \text {, } \\
\mathrm{n}=3 \text {, and } \mathrm{n}=6 \text {, respectively) based on butyrate levels } \\
\text { before and during RS; } B \text {. adolescentis or } R \text {. bromii } \uparrow \\
\text { in enhanced \& high; in } 5 \text { subjects, also } E \text {. rectale } \uparrow ; \text { no } \\
\text { diversity change }\end{array}$ & $\begin{array}{l}\text { Venkataraman et al., } \\
2016\end{array}$ \\
\hline $\begin{array}{l}\text { RS2 (raw unmodified } \\
\text { potato starch) }\end{array}$ & & $\begin{array}{l}\text { AAP-treated bipolar } \\
\text { disorder/ schizophrenic } \\
\text { adult patients }(n=37)\end{array}$ & $\begin{array}{l}\text { Cross-sectional cohort study, control- } \\
\text { habitual diet; } 14 \mathrm{~d}\end{array}$ & $\begin{array}{l}\text { 16S rRNA sequencing } \\
\text { (Illuminia MiSeq platform) }\end{array}$ & $\begin{array}{l}\text { Actinobacteria } \uparrow, \text { Bacteroides \& Parabacteroides } \\
\text { OTUs } \downarrow, \uparrow \text { in RS degraders Bifidobacterium faecale, } \\
\text { B. adolescentis; some individuals } R \text {. bromii \& OTU } \\
\text { Clostridium cluster IV } \uparrow \text {; alpha-diversity no change }\end{array}$ & Flowers et al., 2019 \\
\hline $\begin{array}{l}\text { RS3 versus wheat bran } \\
\text { (NSP) in food }\end{array}$ & $\begin{array}{l}\text { RS } 50-60 \text { or } \\
\text { NSP } 40-54\end{array}$ & $\begin{array}{l}\text { Overweight men }(n=14) ; \\
10 \text { w on different diets }\end{array}$ & $\begin{array}{l}\mathrm{RCT}, \mathrm{CO} ; 7 \text { wk maintenance diet, } 3 \text { wk } \\
\text { intervention, then } 3 \text { wk weight loss diet }\end{array}$ & $\begin{array}{l}\text { 16S rRNA sequencing } \\
\text { (Illumina MiSeq; qPCR for } \\
\text { various genera/ groups } \\
\text { including bifidobacteria, } \\
\text { clostridial clusters (XIV, IV), } \\
\text { Roseburia spp., E. hallii, } 4 \\
\text { bifidobacterial species, total } \\
\text { bacteria; HITChip microarray }\end{array}$ & $\begin{array}{l}\text { Sequencing: Ruminococcus, Roseburia } \uparrow \text { on RS } \\
\text { diet. no effect on Bifidobacterium of RS; no effects } \\
\text { of NSP. HITChip: RS: Ruminococcaceae } \uparrow \text {; NSP: } \\
\text { Lachnospiraceae } \uparrow \text {; RS: diversity } \downarrow\end{array}$ & $\begin{array}{l}\text { Walker et al., 2011; } \\
\text { Salonen et al., } 2014\end{array}$ \\
\hline (RS4) RM in drink & 25,50 & Healthy males $(n=14)$ & $\begin{array}{l}\text { RCT, CO, DB; } 3 \text { treatments: } 50 \mathrm{~g} / \mathrm{d} \\
\text { maltodextrin control, } 25 \mathrm{RM}+25 \\
\mathrm{~g} / \mathrm{d} \text { maltodextrin, } 50 \mathrm{RM}+0 \mathrm{~g} / \mathrm{d} \\
\text { maltodextrin; } 24 \text { d intervention, } \geq 2 \mathrm{wk} \\
\text { WO between }\end{array}$ & $\begin{array}{l}16 \mathrm{~S} \text { rRNA pyrosequencing } \\
\text { ( } 454 \text { titanium); FISH for total } \\
\text { bacteria and major groups of } \\
\text { Bacteroidetes, Clostridiales, } \\
\text { bifidobacteria; qPCR for } \\
\text { bifidobacteria; PCR-DGGE }\end{array}$ & $\begin{array}{l}\text { Sequencing: Ruminococcus, Eubacterium, } \\
\text { Lachnospiraceae, Bacteroides, Holdemania, } \\
\text { Faecalibacterium } \uparrow \text {. FISH, qPCR: no effect on } \\
\text { Bifidobacterium (some bifidobacteria } \uparrow \text { from baseline } \\
\text { for all); PCR-DGGE-band sequencing: OTU related to } \\
\text { Lachnospiraceae }\end{array}$ & $\begin{array}{l}\text { Baer et al., 2014; } \\
\text { Culpepper et al., } 2012\end{array}$ \\
\hline RS4 in flour & $30 \% \mathrm{v} / \mathrm{v}$ & $\begin{array}{l}\text { Adults with metabolic } \\
\text { syndrome signs }(n=20)\end{array}$ & $\begin{array}{l}\mathrm{RCT}, \mathrm{CO}, \mathrm{DB}, \text { placebo-control flour; } \\
2 \times 12 \text { wk, } 2 \text { wk WO }\end{array}$ & $\begin{array}{l}\text { 16S rRNA sequencing } \\
\text { (MiSeq) }\end{array}$ & $\begin{array}{l}\text { Differential abundance of } 71 \text { OTUs, including } \uparrow 3 \\
\text { Bacteroides species, one each of Parabacteroides, } \\
\text { Oscillospira, Blautia, Ruminococcus, Eubacterium \& } \\
\text { Christensenella species }\end{array}$ & $\begin{array}{l}\text { Upadhyaya et al., } \\
2016\end{array}$ \\
\hline
\end{tabular}


K.S. Swanson et al.

Table 6. Continued.

\begin{tabular}{|c|c|c|c|c|c|c|}
\hline Type & Dose g/d & Subjects & Trial design and duration & Technology & Outcome (versus control) & Reference \\
\hline $\begin{array}{l}\text { SCF (RS4) in muffin and } \\
\text { fruit drink }\end{array}$ & 10 or 20 & $\begin{array}{l}\text { Female adolescents (11- } \\
14 \mathrm{y}, \mathrm{n}=30)\end{array}$ & $\begin{array}{l}\text { 3-phase, RCT, DB, CO; placebo- } \\
\text { maltodextrin in beverages, muffins } \\
\text { prepared per the recipe with no } \\
\text { placebo; } 4 \text { wk each treatment, } 3 \text { to } 4 \\
\text { wk WO periods }\end{array}$ & $\begin{array}{l}\text { 16S rRNA sequencing } \\
\text { (Illumina MiSeq) }\end{array}$ & $\begin{array}{l}\text { Bifidobacterium } \uparrow \text { with } 20 \mathrm{~g} / \mathrm{d} \text {; Parabacteroides, } \\
\text { Anaerostipes, Ruminococcus, Lachnospiraceae } \uparrow \text { with } \\
10 \text { and } 20 \mathrm{~g} / \mathrm{d} \text {; Dorea, Dialister } \downarrow \text { with } 20 \mathrm{~g} / \mathrm{d} \text {; diversity } \uparrow \\
\text { with both dosages }\end{array}$ & Whisner et al., 2016 \\
\hline $\begin{array}{l}\text { SCF (RS4); or } \\
\text { as synbiotic with } \\
\text { Lactobacillus } \\
\text { rhamnosus GG or L. } \\
\text { rhamnosus GG-PB12 }\end{array}$ & 6 & Healthy elderly ( $n=37$ ) & $\begin{array}{l}\mathrm{RCT}, \mathrm{DB}, \mathrm{CO} \text {, placebo-maltodextrin; } 2 \\
\text { wk run-in, } 3 \text { wk intervention, } 3 \text { wk WO }\end{array}$ & $\begin{array}{l}\text { 16S rRNA sequencing } \\
\text { (Illumina MiSeq) }\end{array}$ & $\begin{array}{l}\text { SCF: Ruminococcaceae incertae sedis } \uparrow \text {; synbiotic: } \\
\text { Parabacteroides } \uparrow, \text { Ruminococcaceae incertae sedis } \uparrow \text {, } \\
\text { Oscillospira } \downarrow \text {, Desulfovibrio } \downarrow\end{array}$ & Costabile et al., 2017 \\
\hline $\begin{array}{l}\text { PDX or SCF (RS4) in } \\
\text { snack bar }\end{array}$ & $\begin{array}{l}3 \times 7 \text { in } \\
\text { snack bars }\end{array}$ & Healthy males $(n=20)$ & $\begin{array}{l}\text { RCT, DB, CO, placebo-bar with no } \\
\text { supplemental fibre; } 21 \text { d, no WO }\end{array}$ & $\begin{array}{l}\text { 16S rRNA pyrosequencing } \\
\text { (454 Titanium) }\end{array}$ & $\begin{array}{l}\text { Clostridiaceae, Veillonellaceae, } \uparrow \text {; Faecalibacterium } \\
\text { (prausnitzii), Phascolarctobacterium, Dialister } \uparrow \text {; } \\
\text { Eubacteriaceae } \downarrow \text {; Bifidobacterium } \downarrow \text {; SCF only: } \\
\text { Lactobacillus } \uparrow\end{array}$ & Hooda et al., 2012 \\
\hline PDX or SCF (RS4) & 21 & Healthy adult men $(n=21)$ & $\begin{array}{l}\text { RCT, DB, 3-period CO, placebo-bar } \\
\text { with no PDX/SCF; } 21 \text { d }\end{array}$ & $\begin{array}{l}\text { Whole-genome shotgun } \\
\text { pyrosequencing (454) }\end{array}$ & Bacteroidetes $\uparrow$ & Holscher et al., 2015b \\
\hline PDX or PDX + probiotic & 12 & $\begin{array}{l}\text { Obese and overweight } \\
\text { adults }(n=72)\end{array}$ & RCT, DB, P, placebo-cellulose; 6 mo & $\begin{array}{l}\text { 16S rRNA sequencing } \\
\text { (Illumina Miseq) }\end{array}$ & $\begin{array}{l}\text { PDX: } \uparrow \text { Christensenellaceae at } 2,4,6 \text { mo, } \\
\text { Methanobrevibacter, Parabacteroides, Rikenellaceae, } \\
\text { uncultured Ruminococcaeceae at } 2 \text { time points. } \\
\text { PDX+probiotic: Akkermansia } \uparrow \text {, Christensenellaceae } \uparrow \text {, } \\
\text { Methanobrevibacter } \uparrow ; \text { Paraprevotella } \downarrow\end{array}$ & Hibberd et al., 2019 \\
\hline
\end{tabular}


microbiota were analysed by the phylogenetic HITChip microarray and qPCR which again showed marked changes (Salonen et al., 2014). The RS increased relative abundances of multiple phylotypes of Ruminococcaceae, whereas that of most Lachnospiraceae phylotypes were increased in the NSP group. In addition, the RS3 diet decreased the diversity of the microbiota significantly and the dietary responsiveness of the individual's microbiota was inversely associated with its microbiota diversity. Both of these studies noted that RS3 had a marked effect on the microbiota, and that the effect was influenced by the initial microbiota composition of each individual, possibly predisposing them to be a responder or a non-responder (Salonen et al., 2014).

There were five human $16 \mathrm{~S}$ sequencing studies for RS4 (Table 6). The impact of 25 or $50 \mathrm{~g} / \mathrm{d}$ RM (RS4) compared to maltodextrin on faecal microbiota was evaluated using a combination of $16 \mathrm{~S}$ rRNA, FISH, and qPCR (Baer et al., 2014). Sequencing showed significant increases in proportions of various operational taxonomic units (OTUs) matching closest to Ruminococcus, Eubacterium, Lachnospiraceae, Bacteroides, Holdemania and Faecalibacterium, suggesting a broad impact of RM on the gut microbiota. FISH showed that there was a dosedependent increase in total counts of faecal bacteria, and faecal wet and dry weight also increased significantly. In another study, RS4 supplementation was associated with enrichment in relative abundance of numerous species, including P. distasonis, Christensenella minuta, Bacteroides ovatus, Bacteroides xylanisolvens, Bacteroides acidifaciens, Ruminococcus lactaris, B. adolescentis, Eubacterium oxidoreducens and other OTUs within genera Ruminococcus, Blautia, Bacteroides, Oscillospira, and Parabacteroides (Upadhyaya et al., 2016). This study also showed increased relative abundance of Clostridial cluster XIVa, a group which includes taxa associated with the gut mucosal layer (Upadhyaya et al., 2016). Interestingly the RS4 intervention had a significant effect on adipocytokines which play a role in lipid and glucose metabolism and help determine progression to cardiovascular aberrancies (Upadhyaya et al., 2016). In a study with 10 or $20 \mathrm{~g} / \mathrm{d}$ soluble corn fibre (SCF) in pubertal females, significant increases in Bifidobacterium from mean proportion of 3.2 to $5.10 \%$ and Dialister (from 0.5 to $1.2 \%$ ) were found with $20 \mathrm{~g} / \mathrm{d}$, whereas Parabacteroides and Lachnospiraceae proportions increased with both dosages, while Dorea, Anaerostipes and Ruminococcus proportions decreased after consumption of the SCF (Whisner et al., 2016). Significant changes in global microbiota were also reported in elderly subjects upon intervention with $6 \mathrm{~g} / \mathrm{d}$ SCF alone, and in combination with two probiotic strains of Lactobacillus rhamnosus (Costabile et al., 2017).

Three sequencing studies investigated PDX. Impact of both PDX and SCF (RS4) fibres on the composition of faecal microbiota of 20 healthy adult men with a mean dietary fibre intake of $14 \mathrm{~g} / \mathrm{d}$ for $21 \mathrm{~d}$ was studied using 454 sequencing (Hooda et al., 2012). The study showed that the consumption of both fibres led to higher relative abundance of faecal Clostridiaceae and Veillonellaceae, and lower relative abundance of Eubacteriaceae, as compared to the no fibre control. The relative abundance of Faecalibacterium, Phascolarctobacterium and Dialister was greater in response to polydextrose and SCF intake. Among Actinobacteria, relative abundances of the families of Bifidobacteriaceae and Coriobacteriaceae were decreased for both fibres as compared to the control, and the relative abundance of Clostridium and Akkermansia were increased upon PDX consumption, while higher relative abundance of Lactobacillus was observed only in the SCF group. Thus, there were marked effects on the faecal microbiota at the class, genus, and species level due to both fibres. In a follow up study on the same intervention for PDX and SCF, the faecal samples were subjected to whole-genome shotgun pyrosequencing to identify both faecal bacterial populations present and their functional genetic capacity (Holscher et al., 2015b). Both fibres shifted the Bacteroidetes:Firmicutes ratio, significantly increasing the relative abundance of Bacteroidetes (and in particular Porphyromonadaceae) 12 $\pm 2 \%$ (polydextrose) and $13 \pm 2 \%$ (SCF) as compared to the no fibre control. The effects of PDX were also evaluated using FISH, qPCR and DGGE techniques which in fact gave somewhat different outcomes (Costabile et al., 2012). The DGGE data showed that there were significant differences in the indices of the placebo versus the PDX treatment; qPCR analyses showed a significant increase in the butyrate producer Ruminococcus intestinalis, Clostridium histolyticum (clusters I and II) group and Clostridium leptum (cluster IV) for PDX in comparison to the placebo; the FISH analyses did not show significant differences for PDX versus placebo. The most recent human study using sequencing compared $12 \mathrm{~g} / \mathrm{d}$ of PDX with and without a probiotic to cellulose in overweight or obese individuals (Hibberd et al., 2019). The most notable outcome was increased prominent abundance of Christensenellaceae for PDX at the 2, 4 and 6 month end of intervention, also with the probiotic combination, and the latter correlated negatively to waist-area body fat mass after 6 months treatment with LU+B420.

The impact of high and low molecular weight barley beta-glucans on the faecal microbiota of mildly hypercholesterolemia subjects was investigated to determine if there was an association with improving risk factors in cardiovascular disease (Wang et al., 2016). Only the high molecular weight beta-glucans at $3 \mathrm{~g} / \mathrm{d}$ induced shifts, namely increased relative abundance of Bacteroides and decreased Dorea with a reducing trend in Prevotella. This altered profile was associated with a reduction of cardiovascular risk markers, such as BMI, total cholesterol and blood pressure amongst others. Recently, PHGG supplementation in children with autistic spectrum disorder 
showed numerous changes, such as increased relative abundance of Blautia and Acidaminococcus, and decreases in that of Streptococcus, Odoribacter and Eubacterium (family Erysipelotrichaceae) (Inoue et al., 2019). There was significant improvement in 'behaviour irritability' and constipation symptoms in the children. Finally, there were no high-throughput studies evaluating the microbial effects of Arabic gum and konjac glucomannan. However, qPCR based studies showed that consumption of Arabic gum and konjac glucomannan could increase levels of bifidobacteria (Table S5) (Calame et al., 2008; Wu et al., 2011).

\section{Concluding discussion}

The human gut microbiota is emerging as an important factor contributing to human physiology. Microbiota modulation by foods and dietary supplements may provide an attractive way to support health. Dietary fibres and prebiotics by their nature are food for the human colonic microbiota and thereby may play a key role. The establishment of increasingly advanced and cost-effective molecular technologies provides an opportunity to explore the impact of fibres on the human colonic microbiota. Interestingly, based on this review of the $16 \mathrm{~S}$ rRNA-based studies on microbial effects of prebiotics and specific fibres, the inulin-type fructans and GOS, each composed of different monosaccharides, have strong selective bifidogenic effects with apparent lesser effects on the gut microbial community as a whole. Thus, there appears to be no clear relationship between the chemical structure and composition of at least some fibres and their effect on the microbiota, as has been previously noted (Hamaker and Tuncil, 2014). In contrast, numerous broad sequencing technologies show that the glucose-based fibres, such as different RS types and PDX, have broader effects and more diverse effects on the gut microbiota, with notably more stimulation of Ruminococcus spp., specifically $R$. bromii on RS2, as compared to inulin and GOS. This outcome is in line with the outcome of a recent systematic review whereby the subgroup analyses of common prebiotics like inulin and GOS versus other dietary fibres, showed that the common prebiotics led to significantly greater relative abundance of Bifidobacterium and Lactobacillus spp. (So et al., 2018). There are currently insufficient studies on gut microbiota performed for some fibres/NDOs, such as $\beta$-glucans, PHGG, AXOS and XOS and the outcomes reported thus far are not consistent enough to conclude their effects.

The effect of prebiotics, for example inulin-type fructans on specific microbial groups, such as Bifidobacterium spp., Lactobacillus spp., and common pathogenic taxa has been investigated for decades, but the communitywide shifts are only recently investigated. Bifidobacterium spp. is a genus that has coexisted with the mammalian intestine over thousands of years indicating a strong symbiosis between this microbe and the human body (Moeller et al., 2016). Bifidobacteria show broad capacity for carbohydrate breakdown and are well adapted to a glycan-rich environment in the gut (El Kaoutari et al., 2013; Milani et al., 2016). Inulin-type fructans, recognised as prebiotics, were shown to be associated with bifidogenic effects a long time ago (Gibson and Roberfroid, 1995; Hidaka et al., 1986). Such selective effects are confirmed by the newer 16S rRNA-based high-throughput sequencing methods, as shown in this review. Initially inulins were valued for improving digestive health or bowel habit, that has been more recently substantiated by a systematic review (De Vries et al., 2019). Importantly there is an increasing evidence for inulins' role in glucose homeostasis relevant against type 2 diabetes and obesity, amongst several other benefits (Canfora et al., 2015; Koh et al., 2016; Liu et al., 2017b; Slavin, 2013; Stephen et al., 2017; Van de Wouw et al., 2018; Van der Beek et al., 2018). Microbes do not act in isolation and via the process of cross-feeding and other beneficial and/or antagonistic interactions they can influence other members within the community (Tims et al., 2016). This can explain how increases in levels of non-butyrate producing Bifidobacterium can stimulate activity of butyrate producing taxa and thus correlate with higher levels of butyrate production upon fibre intervention providing health benefiting effect to the host (Alfa et al., 2018; Tims et al., 2016). Thus, in order to gain a more comprehensive view on how dietary fibres influence the gut community structure and function, the application of high-throughput and -omics methods became necessary.

The dietary fibre/NDO imposed changes in microbiota composition will especially affect the saccharolytic fermentation and SCFA production, and these effects will benefit the metabolic and physiological status of the host, for example by improving bowel habit or insulin resistance, amongst others (Canfora et al., 2015; Koh et al., 2016). However, the reported changes in microbiota composition in relation to dietary fibre/ NDO intake can be inconsistent between studies and subtle, and individualspecific, as shown in this and other reviews (Makki et al., 2018). The effect of different fibres on microbial diversity clearly varies. For example, the microbial alpha-diversity increased in interventions with SCF (RS4) (Whisner et al., 2016), while the microbial diversity declined when chicory inulin (Reimer et al., 2017; Vandeputte et al., 2017), GOS (Liu et al., 2017a) or RS3 (Salonen et al., 2014) were used. There was no effect on diversity in other human studies for chicory FOS (Tims et al., 2016), GOS (Canfora et al., 2017; Grimaldi et al., 2018; Krumbeck et al., 2018; Liu et al., 2017a), RS2 (Morales et al., 2016; Venkataraman et al., 2016) or RS4 (Upadhyaya et al., 2016). The differences also include the magnitude of changes in abundance of individual taxa (notably Bifidobacterium) and individual differences in responses between study subjects, such as was observed for inulin and (Fuller et al., 2007; Healey et al., 2018; Kolida 
et al., 2007) GOS in several studies (Azcarate-Peril et al., 2017; Davis et al., 2011; Liu et al., 2017a; Pedersen et al., 2016), and FOS (Liu et al., 2017a), and RS3 (Salonen et al., 2014). Subjects' basal diets may also affect responsiveness to inulin-type fructan supplementation as it was observed that the bifidogenic effect seems to be greater in subjects with a high habitually dietary fibre intake (Healey et al., 2018) and those with lower initial bifidobacteria levels (De Preter et al., 2008; Kolida et al., 2007; Tuohy et al., 2001a,b). It was also observed that GOS with higher purity (from 60 to $>95 \%$ of fibre) gave a bifidogenic effect and occasionally other changes, while with GOS of low purity (32\%) there was no bifidogenic effect (Table 5). Thus, the different outcomes between human studies with similar fibres/NDOs, and between responders and non-responders in the studies, may be related to numerous factors, including initial presence/ abundance of keystone microbial species in the community (De Preter et al., 2008; Korpela et al., 2014b; Meyer and Stasse-Wolthuis, 2009; Roberfroid et al., 2010; Salonen et al., 2014), diet (Healey et al., 2018; Salonen et al., 2014), gender (Upadhyaya et al., 2016), intervention length, health status of the subjects, (sufficient) dose of fibres used (Davis et al., 2011; Depeint et al., 2008; Makki et al., 2018) or the form that the fibre is delivered during the study (Francois et al., 2012; Walton et al., 2012). Furthermore aspects of the technologies may also play a role in the discrepancy between outcomes for sequencing studies, for example certain primer pairs may be insufficient for bifidobacteria, and the disruption of bifidobacterial cells to release DNA/ RNA may also affect the detection and levels (Chen et al., 2019; Walker et al., 2015).

Consequently, to understand and address the inconsistencies in research outcomes, a development of systematic approaches to fibre and microbiome studies is needed (Klurfeld et al., 2018). This should include subjects' microbiota screening and stratification at enrolment (Reid et al., 2010), as well as precise characterisation and monitoring of baseline diets used by the study participants, and regular longitudinal microbiota sampling during the intervention. The specific responses to different fibres, as well as proper fibre dosing need to be further investigated. Details of sequencing platforms should be provided. This knowledge could be then applied to support development of systematic approaches in screening of novel dietary fibres and could provide bases for more accurate and relevant definition of prebiotic fibres in the future.

The concept of gut health is complex and it combines diet, microbiota and host mucosa (Valdes et al., 2018). Thus, studies on food ingredients and their effects on microbiota and host require the use of multidisciplinary approaches. The field of microbiota research is rapidly growing due to increasing availability and affordability of novel diagnostics and rising interest from government, industry and public sector. An increasing wealth of technologies with integrated 'omics' approaches are available to study effects of food ingredients on the gut microbiome. Metabolomics and proteomics are capable of detecting and tracking diverse microbial metabolites from different non-digestible food ingredients, discriminating between phenotypes with different inherent microbiota, and potentially diagnosing gastrointestinal state (Jacobs et al., 2009). Metagenomics and metatranscriptomics can characterise the genetic potential and activity of numerous gut microbial species. Systems immunology can be applied to characterise the physiological effect of microbial substrates on markers involved in the inflammatory, autoimmune, allergic and other immune-related conditions in the host (Davis et al., 2017), and to indicate beneficial health outcomes. Thus, integration of several omics techniques is a further step towards a more coherent understanding of the complex microbe-host mutualism. Together all these approaches could lead to identification of a set of biomarkers that could adequately indicate functional presence of beneficial microbes, or their metabolites, and their host effect in relation to specific dietary components (Celi et al., 2018).

In conclusion, the adaptation of high-throughput $16 \mathrm{~S}$ rRNA-based technologies allows superior monitoring of changes in the overall microbial community diversity due to fibre consumption. High microbial diversity contributes to ecosystem stability, resilience and host health. The structural and chemical complexity of carbohydrates in the gut is likely to provide competitive advantage to other taxa adding to the complexity of the fibre mediated responses in the gut community (Hamaker and Tuncil, 2014). The widespread use of Western diets in modern societies has been associated with loss of microbial diversity and large-scale imbalances in the gut microbiota (dysbiosis) (Sonnenburg et al., 2016). Fibres carry a promise to prevent or reverse the diversity loss, and through their microbial effects might even offer therapeutic potential with a wide range of applications, for example in offsetting the negative impacts of antibiotic therapies, facilitating effectiveness of faecal microbiota transplants treatments or alleviating symptoms of inflammatory bowel disease (Wong et al., 2016). Although this review focused on defined added fibres, studies with diets enriched with mixes of dietary fibres are providing valuable information on fibre impact on health. When African Americans were switched from their usual low-fibre/high-fat diet to a high-fibre/low-fat diet, changes in mucosal biomarkers of cancer risk and in aspects of the microbiota and metabolome known to affect cancer risk were observed; there was increased saccharolytic fermentation and production of butyrate and suppression of secondary bile acid synthesis (O'Keefe et al., 2015). Adopting a high-fibre diet in diabetic humans promoted changes in the entire gut microbe community, stimulated the growth of SCFA-producing organisms, and this correlated with elevated levels of glucagon-like peptide-1, a decline in acetylated haemoglobin levels, and 
improved blood-glucose regulation (Zhao et al., 2018). More recently, interventions with whole-grain or white breads were performed which showed that the type of bread that induces the lower glycaemic response in each person could be predicted based solely on microbiome data prior to the intervention. This marked personalisation in both bread digestion and the gut microbiome, strongly suggests that understanding dietary effects requires integration of person-specific factors (Korem et al., 2017). Clearly, there is tremendous promise for prebiotics and fibres directed at the gut microbiome for general nutrition to personalised beneficial effects to improve or maintain human health.

\section{Supplementary material}

Supplementary material can be found online at https://doi. org/10.3920/BM2019.0082.

Table S1. Gut microbiota analyses technologies reviewed by Fraher et al. (2012) and Sekirov et al. (2010).

Table S2. String searches in PubMed (10 Sept 2019) for single/ added fibres and prebiotics.

Table S3. Effect of inulin-type fructans on human gut microbiota composition.

Table S4. Effect of AXOS, GOS and XOS on human gut microbiota composition.

Table S5. Effect of Arabic gum, konjac glucomannan, PDX, PHGG, and RS4 on human gut microbiota composition.

\section{Conflict of interest}

This paper was based on an expert panel discussion held in Chicago in 2016 which was financially supported by Sensus B.V. and a subsistence fee was provided to the following authors: ECM, WMdV, KSS, JG, PDM, JH, and JLS. These authors have no conflict of interest to declare. KB supported updating of the data and writing. EEV is an employee and PDM was a former employee of Sensus. The opinions expressed herein, and the conclusions of this publication are those of the authors.

\section{References}

Aachary, A.A. and Prapulla, S.G., 2010. Xylooligosaccharides (XOS) as an emerging prebiotic: Microbial synthesis, utilization, structural characterization, bioactive properties, and applications. Comprehensive Reviews in Food Science and Food Safety 10: 2-16. https://doi.org/10.1111/j.1541-4337.2010.00135.x
Alfa, M.J., Strang, D., Tappia, P.S., Graham, M., Van Domselaar, G., Forbes, J.D., Laminman, V., Olson, N., DeGagne, P., Bray, D., Murray, B.L., Dufault, B. and Lix, L.M., 2018. A randomized trial to determine the impact of a digestion resistant starch composition on the gut microbiome in older and mid-age adults. Clinical Nutrition 37: 797-807. https://doi.org/10.1016/j.clnu.2017.03.025

Almeida, A., Mitchell, A.L., Boland, M., Forster, S.C., Gloor, G.B., Tarkowska, A., Lawley, T.D. and Finn, R.D., 2019. A new genomic blueprint of the human gut microbiota. Nature: 568: 499-504.

Azcarate-Peril, M.A., Ritter, A.J., Savaiano, D., Monteagudo-Mera, A., Anderson, C., Magness, S.T. and Klaenhammer, T.R., 2017. Impact of short-chain galactooligosaccharides on the gut microbiome of lactose-intolerant individuals. Proceedings of the National Academy of Sciences of the USA 114: E367-E375. https://doi.org/10.1073/ pnas. 1606722113

Baer, D.J., Stote, K.S., Henderson, T., Paul, D.R., Okuma, K., Tagami, H., Kanahori, S., Gordon, D.T., Rumpler, W.V., Ukhanova, M., Culpepper, T., Wang, X. and Mai, V., 2014. The metabolizable energy of dietary resistant maltodextrin is variable and alters fecal microbiota composition in adult men. Journal of Nutrition 144: 1023-1029. https://doi.org/10.3945/jn.113.185298

Baxter, N.T., Schmidt, A.W., Venkataraman, A., Kim, K.S., Waldron, C. and Schmidt, T.M., 2019. Dynamics of human gut microbiota and short-chain fatty acids in response to dietary interventions with three fermentable fibers. mBio 10: e02566-02518.

Belenguer, A., Duncan, S.H., Calder, A.G., Holtrop, G., Louis, P., Lobley, G.E. and Flint, H.J., 2006. Two routes of metabolic cross-feeding between Bifidobacterium adolescentis and butyrate-producing anaerobes from the human gut. Applied and Environmental Microbiology 72: 3593.

Benítez-Páez, A., Kjølbæk, L., Del Pulgar, E.M.G., Brahe, L.K., Astrup, A., Matysik, S., Schött, H.-F., Krautbauer, S., Liebisch, G. and Boberska, J., 2019. A multi-omics approach to unraveling the microbiome-mediated effects of arabinoxylan oligosaccharides in overweight humans. Msystems 4: e00209-00219.

Benjamin, J.L., Hedin, C.R., Koutsoumpas, A., Ng, S.C., McCarthy, N.E., Hart, A.L., Kamm, M.A., Sanderson, J.D., Knight, S.C., Forbes, A., Stagg, A.J., Whelan, K. and Lindsay, J.O., 2011. Randomised, double-blind, placebo-controlled trial of fructo-oligosaccharides in active Crohn's disease. Gut 60: 923-929. https://doi.org/10.1136/ gut.2010.232025

Blædel, T., Holm, J.B., Sundekilde, U.K., Schmedes, M.S., Hess, A.L., Lorenzen, J.K., Kristiansen, K., Dalsgaard, T.K., Astrup, A. and Larsen, L.H., 2016. A randomised, controlled, crossover study of the effect of diet on angiopoietin-like protein 4 (ANGPTL4) through modification of the gut microbiome. Journal of Nutritional Science 5: e45.

Bogovic Matijasic, B., Obermajer, T., Lipoglavsek, L., Sernel, T., Locatelli, I., Kos, M., Smid, A. and Rogelj, I., 2016. Effects of synbiotic fermented milk containing Lactobacillus acidophilus La-5 and Bifidobacterium animalis ssp. lactis BB-12 on the fecal microbiota of adults with irritable bowel syndrome: a randomized double-blind, placebo-controlled trial. Journal of Dairy Science 99: 5008-5021. https://doi.org/10.3168/jds.2015-10743 
Calame, W., Weseler, A.R., Viebke, C., Flynn, C. and Siemensma, A.D., 2008. Gum arabic establishes prebiotic functionality in healthy human volunteers in a dose-dependent manner. British Journal of Nutrition 100: 1269-1275. https://doi.org/10.1017/ s0007114508981447

Canfora, E.E., Jocken, J.W. and Blaak, E.E., 2015. Short-chain fatty acids in control of body weight and insulin sensitivity. Nature Reviews Endocrinology 11: 577-591. https://doi.org/10.1038/ nrendo.2015.128

Canfora, E.E., Van der Beek, C.M., Hermes, G.D.A., Goossens, G.H., Jocken, J.W.E., Holst, J.J., Van Eijk, H.M., Venema, K., Smidt, H., Zoetendal, E.G. Dejong, C.H.C., Lenaerts, K. and Blaak, E.E., 2017. Supplementation of diet with galacto-oligosaccharides increases bifidobacteria, but not insulin sensitivity, in obese prediabetic individuals. Gastroenterology 153: 87-97. https://doi.org/10.1053/j. gastro.2017.03.051

Carranza, C.O., Fernandez, A.Á., Armendáriz, G.R.B. and LópezMunguía, A., 2015. Processing of fructans and oligosaccharides from Agave plants. Processing and impact on active components in food. Elsevier, New York, NY, USA, pp. 121-129.

Celi, P., Verlhac, V., Pérez Calvo, E., Schmeisser, J. and Kluenter, A.M., 2018. Biomarkers of gastrointestinal functionality in animal nutrition and health. Animal Feed Science and Technology 250: 9-31. https://doi.org/10.1016/j.anifeedsci.2018.07.012

Chen, Z., Hui, P.C., Hui, M., Yeoh, Y.K., Wong, P.Y., Chan, M.C., Wong, M.C., Ng, S.C., Chan, F.K. and Chan, P.K., 2019. Impact of preservation method and $16 \mathrm{~S}$ rRNA hypervariable region on gut microbiota profiling. Msystems 4: e00271-00218.

Costabile, A., Bergillos-Meca, T., Rasinkangas, P., Korpela, K., De Vos, W.M. and Gibson, G.R., 2017. Effects of soluble corn fiber alone or in synbiotic combination with Lactobacillus rhamnosus GG and the pilus-deficient derivative GG-PB12 on fecal microbiota, metabolism, and markers of immune function: a randomized, double-blind, placebo-controlled, crossover study in healthy elderly (Saimes Study). Frontiers in Immunology 8: 1443-1443. https://doi. org/10.3389/fimmu.2017.01443

Costabile, A., Fava, F., Roytio, H., Forssten, S.D., Olli, K., Klievink, J., Rowland, I.R., Ouwehand, A.C., Rastall, R.A., Gibson, G.R. and Walton, G.E., 2012. Impact of polydextrose on the faecal microbiota: a double-blind, crossover, placebo-controlled feeding study in healthy human subjects. British Journal of Nutrition 108: 471-481. https://doi.org/10.1017/s0007114511005782

Cotillard, A., Kennedy, S.P., Kong, L.C., Prifti, E., Pons, N., Le Chatelier, E., Almeida, M., Quinquis, B., Levenez, F. and Galleron, N., 2013. Dietary intervention impact on gut microbial gene richness. Nature 500: 585.

Coulier, L., Timmermans, J., Bas, R., Van den Dool, R., Haaksman, I., Klarenbeek, B., Slaghek, T. and Van Dongen, W., 2009. Indepth characterization of prebiotic galacto-oligosaccharides by a combination of analytical techniques. Journal of Agricultural and Food Chemistry 57: 8488-8495. https://doi.org/10.1021/jf902549e

Craig, S.A.S., Holden, J.F., Troup, J.P., Auerbach, M.H. and Frier, H., 1998. Polydextrose as soluble fiber: physiological and analytical aspects. Cereal Foods World 43: 370-376.
Culpepper, T., Ukhanova, M., Baer, D.J., Kanahori, S., Okuma, K., Tagami, H., Gordon, D. and Mai, V., 2012. Fecal microbiota composition is affected by resistant maltodextrin, and bifidobacteria counts correlate with energy gain. Dietary fiber and health. Taylor \& Francis, Abingdon, UK.

Davis, L.M., Martinez, I., Walter, J., Goin, C. and Hutkins, R.W., 2011. Barcoded pyrosequencing reveals that consumption of galactooligosaccharides results in a highly specific bifidogenic response in humans. PLoS ONE 6: e25200. https://doi.org/10.1371/ journal.pone.0025200

Davis, L.M., Martinez, I., Walter, J. and Hutkins, R., 2010. A dose dependent impact of prebiotic galactooligosaccharides on the intestinal microbiota of healthy adults. International Journal of Food Microbiology 144: 285-292. https://doi.org/10.1016/j. ijfoodmicro.2010.10.007

Davis, M.M., Tato, C.M. and Furman, D., 2017. Systems immunology: just getting started. Nature Immunology 18: 725-732. https://doi. org/10.1038/ni.3768

De Preter, V., Vanhoutte, T., Huys, G., Swings, J., Rutgeerts, P. and Verbeke, K., 2008. Baseline microbiota activity and initial bifidobacteria counts influence responses to prebiotic dosing in healthy subjects. Alimentary Pharmacology \& Therapeutics 27: 504-513. https://doi.org/10.1111/j.1365-2036.2007.03588.x

De Vries, J., Le Bourgot, C., Calame, W. and Respondek, F., 2019. Effects of $\beta$-fructans fiber on bowel function: a systematic review and meta-analysis. Nutrients 11: 91.

Debelius, J.W., Vázquez-Baeza, Y., McDonald, D., Xu, Z., Wolfe, E. and Knight, R., 2016. Turning participatory microbiome research into usable data: lessons from the American Gut Project. Journal of Microbiology and Biology Education 17: 46.

Delcour, J.A., Aman, P., Courtin, C.M., Hamaker, B.R. and Verbeke, K., 2016. Prebiotics, fermentable dietary fiber, and health claims. Advanced Nutrition 7: 1-4. https://doi.org/10.3945/an.115.010546

Depeint, F., Tzortzis, G., Vulevic, J., I'Anson, K. and Gibson, G.R., 2008. Prebiotic evaluation of a novel galactooligosaccharide mixture produced by the enzymatic activity of Bifidobacterium bifidum NCIMB 41171, in healthy humans: a randomized, doubleblind, crossover, placebo-controlled intervention study. American Journal of Clinical Nutrition 87: 785-791. https://doi.org/10.1093/ ajcn/87.3.785

Dewulf, E.M., Cani, P.D., Claus, S.P., Fuentes, S., Puylaert, P.G., Neyrinck, A.M., Bindels, L.B., De Vos, W.M., Gibson, G.R., Thissen, J.P. and Delzenne, N.M., 2013. Insight into the prebiotic concept: lessons from an exploratory, double blind intervention study with inulin-type fructans in obese women. Gut 62: 1112-1121. https:// doi.org/10.1136/gutjnl-2012-303304

Duncan, S.H., Louis, P. and Flint, H.J., 2004. Lactate-utilizing bacteria, isolated from human feces, that produce butyrate as a major fermentation product. Applied and Environmental Microbiology 70: 5810-5817. https://doi.org/10.1128/aem.70.10.5810-5817.2004 
European Commission, 2011. Regulation (EU) No 1169/2011 of the European Parliament and of the Council of 25 October 2011 on the provision of food information to consumers, amending Regulations (EC) No 1924/2006 and (EC) No 1925/2006 of the European Parliament and of the Council, and repealing Commission Directive 87/250/EEC, Council Directive 90/496/EEC, Commission Directive 1999/10/EC, Directive 2000/13/EC of the European Parliament and of the Council, Commission Directives 2002/67/ EC and 2008/5/EC and Commission Regulation (EC) No 608/2004. Official Journal of the EU L 304: 18-63. Available at: http://data. europa.eu/eli/reg/2011/1169/oj

El Kaoutari, A., Armougom, F., Gordon, J.I., Raoult, D. and Henrissat, B., 2013. The abundance and variety of carbohydrate-active enzymes in the human gut microbiota. Nature Reviews Microbiology 11: 497-504. https://doi.org/10.1038/nrmicro3050

Falony, G., Joossens, M., Vieira-Silva, S., Wang, J., Darzi, Y., Faust, K., Kurilshikov, A., Bonder, M.J., Valles-Colomer, M., Vandeputte, D., Tito, R.Y., Chaffron, S., Rymenans, L., Verspecht, C., De Sutter, L., Lima-Mendez, G., D’Hoe, K., Jonckheere, K., Homola, D., Garcia, R., Tigchelaar, E.F., Eeckhaudt, L., Fu, J., Henckaerts, L., Zhernakova, A., Wijmenga, C. and Raes, J., 2016. Population-level analysis of gut microbiome variation. Science 352: 560-564. https:// doi.org/10.1126/science.aad3503

Food and Agriculture Organisation / World Health Organisation (FAO/WHO), 2010. CODEX Alimentarius - Guidelines on nutrition labelling. FAO/WHO, Rome, Italy. Available at: https://tinyurl. com/rqp2bkv

Food and Drug Administration (FDA), 2016. Food labeling: revision of the nutrition and supplement facts label 21 CFR 101. Available at: https://tinyurl.com/n2mosmm

Finegold, S.M., Li, Z., Summanen, P.H., Downes, J., Thames, G., Corbett, K., Dowd, S., Krak, M. and Heber, D., 2014. Xylooligosaccharide increases bifidobacteria but not lactobacilli in human gut microbiota. Food and Function 5: 436-445. https://doi.org/10.1039/c3fo60348b

Flowers, S.A., Baxter, N.T., Ward, K.M., Kraal, A.Z., McInnis, M.G., Schmidt, T.M. and Ellingrod, V.L., 2019. Effects of atypical antipsychotic treatment and resistant starch supplementation on gut microbiome composition in a cohort of patients with bipolar disorder or schizophrenia. Pharmacotherapy 39: 161-170.

Fraher, M.H., O’Toole, P.W. and Quigley, E.M.M., 2012. Techniques used to characterize the gut microbiota: a guide for the clinician. Nature Reviews Gastroenterology and Hepatology 9: 312.

Francois, I.E., Lescroart, O., Veraverbeke, W.S., Marzorati, M., Possemiers, S., Evenepoel, P., Hamer, H., Houben, E., Windey, K., Welling, G.W., Delcour, J.A., Courtin, C.M., Verbeke, K. and Broekaert, W.F., 2012. Effects of a wheat bran extract containing arabinoxylan oligosaccharides on gastrointestinal health parameters in healthy adult human volunteers: a double-blind, randomised, placebo-controlled, cross-over trial. British Journal of Nutrition 108: 2229-2242. https://doi.org/10.1017/s0007114512000372

Fuller, Z., Louis, P., Mihajlovski, A., Rungapamestry, V., Ratcliffe, B. and Duncan, A.J., 2007. Influence of cabbage processing methods and prebiotic manipulation of colonic microflora on glucosinolate breakdown in man. British Journal of Nutrition 98: 364-372. https:// doi.org/10.1017/s0007114507709091
Gibson, G.R., Hutkins, R., Sanders, M.E., Prescott, S.L., Reimer, R.A., Salminen, S.J., Scott, K., Stanton, C., Swanson, K.S., Cani, P.D., Verbeke, K. and Reid, G., 2017. Expert consensus document. The International Scientific Association for Probiotics and Prebiotics (ISAPP) consensus statement on the definition and scope of prebiotics. Nature Reviews Gastroenterology and Hepatology 14: 491-502. https://doi.org/10.1038/nrgastro.2017.75

Gibson, G.R. and Roberfroid, M.B., 1995. Dietary modulation of the human colonic microbiota: introducing the concept of prebiotics. Journal of Nutrition 125: 1401-1412. https://doi.org/10.1093/ jn/125.6.1401

Grimaldi, R., Gibson, G.R., Vulevic, J., Giallourou, N., Castro-Mejia, J.L., Hansen, L.H., Leigh Gibson, E., Nielsen, D.S. and Costabile, A., 2018. A prebiotic intervention study in children with autism spectrum disorders (ASDs). Microbiome 6: 133. https://doi. org/10.1186/s40168-018-0523-3

Hadrich, D., 2018. Microbiome research is becoming the key to better understanding health and nutrition. Frontiers in Genetics 9: 212212. https://doi.org/10.3389/fgene.2018.00212

Hald, S., Schioldan, A.G., Moore, M.E., Dige, A., Lærke, H.N., Agnholt, J., Knudsen, K.E.B., Hermansen, K., Marco, M.L. and Gregersen, S., 2016. Effects of arabinoxylan and resistant starch on intestinal microbiota and short-chain fatty acids in subjects with metabolic syndrome: a randomised crossover study. PLoS ONE 11: e0159223.

Hamaker, B.R. and Tuncil, Y.E., 2014. A perspective on the complexity of dietary fiber structures and their potential effect on the gut microbiota. Journal of Molecular Biology 426: 3838-3850. https:// doi.org/10.1016/j.jmb.2014.07.028

Healey, G., Murphy, R., Butts, C., Brough, L., Whelan, K. and Coad, J., 2018. Habitual dietary fibre intake influences gut microbiota response to an inulin-type fructan prebiotic: a randomised, doubleblind, placebo-controlled, cross-over, human intervention study. British Journal of Nutrition 119: 176-189. https://doi.org/10.1017/ s0007114517003440

Heintz-Buschart, A. and Wilmes, P., 2018. Human gut microbiome: function matters. Trends in Microbiology 26: 563-574. https://doi. org/10.1016/j.tim.2017.11.002

Hibberd, A., Yde, C., Ziegler, M., Honoré, A., Saarinen, M., Lahtinen, S., Stahl, B., Jensen, H. and Stenman, L., 2019. Probiotic or synbiotic alters the gut microbiota and metabolism in a randomised controlled trial of weight management in overweight adults. Beneficial Microbes 10: 121-135.

Hidaka, H., Eida, T., Takizawa, T., Tokunaga, T. and Tashiro, Y., 1986. Effects of fructooligosaccharides on intestinal flora and human health. Bifidobacteria and Microflora 5: 37-50. https://doi. org/10.12938/bifidus1982.5.1_37

Hiergeist, A., Gläsner, J., Reischl, U. and Gessner, A., 2015. Analyses of intestinal microbiota: culture versus sequencing. ILAR Journal 56: 228-240.

Hirayama, M. and Hidaka, H., 1993. Production and utilization of microbial fructans. Science and technology of fructans. CRC Press, Boca Raton, FL, USA, pp. 273-302. 
Ho, J., Nicolucci, A.C., Virtanen, H., Schick, A., Meddings, J., Reimer, R.A. and Huang, C., 2019. Effect of prebiotic on microbiota, intestinal permeability and glycemic control in children with type 1 diabetes. Journal of Clinical Endocrinology and Metabolism 104: 4427-4440. https://doi.org/10.1210/jc.2019-00481

Holscher, H.D., Bauer, L.L., Gourineni, V., Pelkman, C.L., Fahey Jr., G.C. and Swanson, K.S., 2015a. Agave inulin supplementation affects the fecal microbiota of healthy adults participating in a randomized, double-blind, placebo-controlled, crossover trial. Journal of Nutrition 145: 2025-2032. https://doi.org/10.3945/ jn.115.217331

Holscher, H.D., Caporaso, J.G., Hooda, S., Brulc, J.M., Fahey Jr., G.C. and Swanson, K.S., 2015b. Fiber supplementation influences phylogenetic structure and functional capacity of the human intestinal microbiome: follow-up of a randomized controlled trial. American Journal of Clinical Nutrition 101: 55-64. https://doi. org/10.3945/ajcn.114.092064

Homayouni, A., Amini, A., Keshtiban, A.K., Mortazavian, A.M., Esazadeh, K. and Pourmoradian, S., 2014. Resistant starch in food industry: a changing outlook for consumer and producer. StarchStärke 66: 102-114.

Hooda, S., Boler, B.M., Serao, M.C., Brulc, J.M., Staeger, M.A., Boileau, T.W., Dowd, S.E., Fahey Jr., G.C. and Swanson, K.S., 2012. 454 pyrosequencing reveals a shift in fecal microbiota of healthy adult men consuming polydextrose or soluble corn fiber. Journal of Nutrition 142: 1259-1265. https://doi.org/10.3945/jn.112.158766

Hornung, B., Martins dos Santos, V.A.P., Smidt, H. and Schaap, P.J., 2018. Studying microbial functionality within the gut ecosystem by systems biology. Genes and Nutrition 13: 5. https://doi.org/10.1186/ s12263-018-0594-6

Human Microbiome Project Consortium, 2012a. Structure, function and diversity of the healthy human microbiome. Nature 486: 207-214.

Human Microbiome Project Consortium, 2012b. A framework for human microbiome research. Nature 486: 215-221.

Inoue, R., Sakaue, Y., Kawada, Y., Tamaki, R., Yasukawa, Z., Ozeki, M., Ueba, S., Sawai, C., Nonomura, K. and Tsukahara, T., 2019. Dietary supplementation with partially hydrolyzed guar gum helps improve constipation and gut dysbiosis symptoms and behavioral irritability in children with autism spectrum disorder. Journal of Clinical Biochemistry and Nutrition 64: 217-223.

Jacobs, D.M., Gaudier, E., Van Duynhoven, J. and Vaughan, E.E., 2009. Non-digestible food ingredients, colonic microbiota and the impact on gut health and immunity: a role for metabolomics. Current Drug Metabolism 10: 41-54.

Joossens, M., Huys, G., Van Steen, K., Cnockaert, M., Vermeire, S., Rutgeerts, P., Verbeke, K., Vandamme, P. and De Preter, V., 2011. High-throughput method for comparative analysis of denaturing gradient gel electrophoresis profiles from human fecal samples reveals significant increases in two bifidobacterial species after inulin-type prebiotic intake. FEMS Microbiology Ecology 75: 343349. https://doi.org/10.1111/j.1574-6941.2010.01008.x

Kim, M. and Tagkopoulos, I., 2018. Data integration and predictive modeling methods for multi-omics datasets. Molecular Omics 14: 8-25. https://doi.org/10.1039/c7mo00051k
King, C.H., Desai, H., Sylvetsky, A.C., LoTempio, J., Ayanyan, S., Carrie, J., Crandall, K.A., Fochtman, B.C., Gasparyan, L. and Gulzar, N., 2019. Baseline human gut microbiota profile in healthy people and standard reporting template. PLoS ONE 14: e0206484.

Klurfeld, D.M., Davis, C.D., Karp, R.W., Allen-Vercoe, E., Chang, E.B., Chassaing, B., Fahey, G.C., Hamaker, B.R., Holscher, H.D., Lampe, J.W., Marette, A., Martens, E., O’Keefe, S.J., Rose, D.J., Saarela, M., Schneeman, B.O., Slavin, J.L., Sonnenburg, J.L., Swanson, K.S., Wu, G.D. and Lynch, C.J., 2018. Considerations for best practices in studies of fiber or other dietary components and the intestinal microbiome. American Journal of Physiology - Endocrinology and Metabolism 315: E1087-E109. https://doi.org/10.1152/ ajpendo.00058.2018

Knol, J., Scholtens, P., Kafka, C., Steenbakkers, J., Gro, S., Helm, K., Klarczyk, M., Schopfer, H., Bockler, H.M. and Wells, J., 2005. Colon microflora in infants fed formula with galacto- and fructooligosaccharides: more like breast-fed infants. Journal of Pediatric Gastroenterology and Nutrition 40: 36-42.

Koh, A., De Vadder, F., Kovatcheva-Datchary, P. and Backhed, F., 2016. From dietary fiber to host physiology: short-chain fatty acids as key bacterial metabolites. Cell 165: 1332-1345. https://doi.org/10.1016/j. cell.2016.05.041

Kolida, S., Meyer, D. and Gibson, G.R., 2007. A double-blind placebocontrolled study to establish the bifidogenic dose of inulin in healthy humans. European Journal of Clinical Nutrition 61: 1189-1195. https://doi.org/10.1038/sj.ejcn.1602636

Korem, T., Zeevi, D., Zmora, N., Weissbrod, O., Bar, N., Lotan-Pompan, M., Avnit-Sagi, T., Kosower, N., Malka, G. and Rein, M., 2017. Bread affects clinical parameters and induces gut microbiome-associated personal glycemic responses. Cell Metabolism 25: 1243-1253.

Korpela, K., Flint, H.J., Johnstone, A.M., Lappi, J., Poutanen, K., Dewulf, E., Delzenne, N., De Vos, W.M. and Salonen, A., 2014a. Gut microbiota signatures predict host and microbiota responses to dietary interventions in obese individuals. PLoS ONE 9: e90702.

Korpela, K., Flint, H.J., Johnstone, A.M., Lappi, J., Poutanen, K., Dewulf, E., Delzenne, N., De Vos, W.M. and Salonen, A., 2014b. Gut microbiota signatures predict host and microbiota responses to dietary interventions in obese individuals. PLoS ONE 9: e90702. https://doi.org/10.1371/journal.pone.0090702

Krumbeck, J.A., Rasmussen, H.E., Hutkins, R.W., Clarke, J., Shawron, K., Keshavarzian, A. and Walter, J., 2018. Probiotic Bifidobacterium strains and galactooligosaccharides improve intestinal barrier function in obese adults but show no synergism when used together as synbiotics. Microbiome 6: 121. https://doi.org/10.1186/s40168018-04.94-4

Kumar, K.R., Cowley, M.J. and Davis, R.L., 2019. Next-generation sequencing and emerging technologies. Seminars in thrombosis and hemostasis. Thieme Medical Publishers, New York, NY, USA.

Ladirat, S.E., Schoterman, M.H., Rahaoui, H., Mars, M., Schuren, F.H., Gruppen, H., Nauta, A. and Schols, H.A., 2014. Exploring the effects of galacto-oligosaccharides on the gut microbiota of healthy adults receiving amoxicillin treatment. British Journal of Nutrition 112: 536-546. https://doi.org/10.1017/s0007114514001135 
Laffin, M.R., Tayebi Khosroshahi, H., Park, H., Laffin, L.J., Madsen, K., Kafil, H.S., Abedi, B., Shiralizadeh, S. and Vaziri, N.D., 2019. Amylose resistant starch (HAM-RS2) supplementation increases the proportion of Faecalibacterium bacteria in end-stage renal disease patients: Microbial analysis from a randomized placebo-controlled trial. Hemodialysis International 23(3): 343-347.

Lagier, J.-C., Khelaifia, S., Alou, M.T., Ndongo, S., Dione, N., Hugon, P., Caputo, A., Cadoret, F., Traore, S.I., Seck, E.H., Dubourg, G., Durand, G., Mourembou, G., Guilhot, E., Togo, A., Bellali, S., Bachar, D., Cassir, N., Bittar, F., Delerce, J., Mailhe, M., Ricaboni, D., Bilen, M., Dangui Nieko, N.P.M., Dia Badiane, N.M., Valles, C., Mouelhi, D., Diop, K., Million, M., Musso, D., Abrahão, J., Azhar, E.I., Bibi, F., Yasir, M., Diallo, A., Sokhna, C., Djossou, F., Vitton, V., Robert, C., Rolain, J.M., La Scola, B., Fournier, P.-E., Levasseur, A. and Raoult, D., 2016. Culture of previously uncultured members of the human gut microbiota by culturomics. Nature Microbiology 1: 16203.

Lagkouvardos, I., Overmann, J. and Clavel, T., 2017. Cultured microbes represent a substantial fraction of the human and mouse gut microbiota. Gut Microbes 8: 493-503. https://doi.org/10.1080/1 9490976.2017.1320468

Le Chatelier, E., Nielsen, T., Qin, J., Prifti, E., Hildebrand, F., Falony, G., Almeida, M., Arumugam, M., Batto, J.-M. and Kennedy, S., 2013. Richness of human gut microbiome correlates with metabolic markers. Nature 500: 541.

Lim, M.Y., Rho, M., Song, Y.-M., Lee, K., Sung, J. and Ko, G., 2014. Stability of gut enterotypes in Korean monozygotic twins and their association with biomarkers and diet. Scientific Reports 4: 7348.

Liu, F., Li, P., Chen, M., Luo, Y., Prabhakar, M., Zheng, H., He, Y., Qi, Q., Long, H., Zhang, Y., Sheng, H. and Zhou, H., 2017a. Fructooligosaccharide (FOS) and galactooligosaccharide (GOS) increase Bifidobacterium but reduce butyrate producing bacteria with adverse glycemic metabolism in healthy young population. Scientific Reports 7: 11789-11789. https://doi.org/10.1038/s41598017-10722-2

Liu, F., Prabhakar, M., Ju, J., Long, H. and Zhou, H., 2017b. Effect of inulin-type fructans on blood lipid profile and glucose level: a systematic review and meta-analysis of randomized controlled trials. European Journal of Clinical Nutrition 71: 9.

Lohner, S., Jakobik, V., Mihalyi, K., Soldi, S., Vasileiadis, S., Theis, S., Sailer, M., Sieland, C., Berenyi, K., Boehm, G. and Decsi, T., 2018. Inulin-type fructan supplementation of 3- to 6-year-old children is associated with higher fecal Bifidobacterium concentrations and fewer febrile episodes requiring medical attention. Journal of Nutrition 148: 1300-1308. https://doi.org/10.1093/jn/nxy120

Lomax, A.R., Cheung, L.V., Noakes, P.S., Miles, E.A. and Calder, P.C., 2015. Inulin-type $\beta 2-1$ fructans have some effect on the antibody response to seasonal influenza vaccination in healthy middle-aged humans. Frontiers in Immunology 6: 490.

Lomax, A.R., Cheung, L.V., Tuohy, K.M., Noakes, P.S., Miles, E.A. and Calder, P.C., 2012. $\beta 2-1$ Fructans have a bifidogenic effect in healthy middle-aged human subjects but do not alter immune responses examined in the absence of an in vivo immune challenge: results from a randomised controlled trial. British Journal of Nutrition 108: 1818-1828. https://doi.org/10.1017/s0007114511007276
Louis, P., Young, P., Holtrop, G. and Flint, H.J., 2010. Diversity of human colonic butyrate-producing bacteria revealed by analysis of the butyryl-CoA:acetate CoA-transferase gene. Environmental Microbiology 12: 304-314. https://doi.org/10.1111/j.14622920.2009.02066.x

Maier, T.V., Lucio, M., Lee, L.H., VerBerkmoes, N.C., Brislawn, C.J., Bernhardt, J., Lamendella, R., McDermott, J.E., Bergeron, N., Heinzmann, S.S., Morton, J.T., González, A., Ackermann, G., Knight, R., Riedel, K., Krauss, R.M., Schmitt-Kopplin, P. and Jansson, J.K., 2017. Impact of dietary resistant starch on the human gut microbiome, metaproteome, and metabolome. mBio 8: e0134301317. https://doi.org/10.1128/mBio.01343-17

Makki, K., Deehan, E.C., Walter, J. and Bäckhed, F., 2018. The impact of dietary fiber on gut microbiota in host health and disease. Cell Host and Microbe 23: 705-715. https://doi.org/10.1016/j. chom.2018.05.012

Martinez, I., Kim, J., Duffy, P.R., Schlegel, V.L. and Walter, J., 2010. Resistant starches types 2 and 4 have differential effects on the composition of the fecal microbiota in human subjects. PLoS ONE 5: e15046. https://doi.org/10.1371/journal.pone.0015046

McLoughlin, R., Berthon, B.S., Rogers, G.B., Baines, K.J., Leong, L.E., Gibson, P.G., Williams, E.J. and Wood, L.G., 2019. Soluble fibre supplementation with and without a probiotic in adults with asthma: a 7-day randomised, double blind, three way cross-over trial. EBioMedicine 46: 473-485.

Mensink, M.A., Frijlink, H.W., Van der Voort Maarschalk, K. and Hinrichs, W.L., 2015. Inulin, a flexible oligosaccharide I: review of its physicochemical characteristics. Carbohydrate Polymers 130: 405-419.

Meyer, D. and Stasse-Wolthuis, M., 2009. The bifidogenic effect of inulin and oligofructose and its consequences for gut health. European Journal of Clinical Nutrition 63: 1277-1289. https://doi. org/10.1038/ejcn.2009.64

Meyer, D., De Wolf, J. and Olivier, P., 2007. Inulin und fructooligosaccharide. In: Rosenplenter, K. and Nöhle U. (eds.) Handbuch Süßungsmittel. Behr's Verlag, Hamburg, Germany, E pp.155-193.

Meyer, D., Vermulst, J., Tromp, R.H. and De Hoog, E.H.A., 2011. The effect of inulin on tribology and sensory profiles of skimmed milk. Journal of Texture Studies 42: 387-393. https://doi.org/10.1111/ j.1745-4603.2011.00298.x

Micka, A., Siepelmeyer, A., Holz, A., Theis, S. and Schön, C., 2017. Effect of consumption of chicory inulin on bowel function in healthy subjects with constipation: a randomized, double-blind, placebo-controlled trial. International Journal of Food Sciences and Nutrition 68: 82-89.

Milani, C., Turroni, F., Duranti, S., Lugli, G.A., Mancabelli, L., Ferrario, C., Van Sinderen, D. and Ventura, M., 2016. Genomics of the genus Bifidobacterium reveals species-specific adaptation to the glycanrich gut environment. Applied and Environmental Microbiology 82: 980-991. https://doi.org/10.1128/aem.03500-15

Moeller, A.H., Caro-Quintero, A., Mjungu, D., Georgiev, A.V., Lonsdorf, E.V., Muller, M.N., Pusey, A.E., Peeters, M., Hahn, B.H. and Ochman, H., 2016. Cospeciation of gut microbiota with hominids. Science 353: 380-382. 
Morales, P., Fujio, S., Navarrete, P., Ugalde, J.A., Magne, F., CarrascoPozo, C., Tralma, K., Quezada, M., Hurtado, C., Covarrubias, N., Brignardello, J., Henriquez, D. and Gotteland, M., 2016. Impact of dietary lipids on colonic function and microbiota: an experimental approach involving orlistat-induced fat malabsorption in human volunteers. Clinical and Translational Gastroenterology 7: e161. https://doi.org/10.1038/ctg.2016.20

Mudgil, D., Barak, S. and Khatkar, B.S., 2014. Guar gum: processing, properties and food applications - a review. Journal of Food Science and Technology 51: 409-418.

Nicolucci, A.C., Hume, M.P., Martinez, I., Mayengbam, S., Walter, J. and Reimer, R.A., 2017. Prebiotics reduce body fat and alter intestinal microbiota in children who are overweight or with obesity. Gastroenterology 153: 711-722. https://doi.org/10.1053/j. gastro.2017.05.055

O’Keefe, S.J.D., Li, J.V., Lahti, L., Ou, J., Carbonero, F., Mohammed, K., Posma, J.M., Kinross, J., Wahl, E., Ruder, E., Vipperla, K., Naidoo, V., Mtshali, L., Tims, S., Puylaert, P.G.B., Delany, J., Krasinskas, A., Benefiel, A.C., Kaseb, H.O., Newton, K., Nicholson, J.K., De Vos, W.M., Gaskins, H.R. and Zoetendal, E.G. 2015. Fat, fibre and cancer risk in African Americans and rural Africans. Nature Communications 6: 6342. https://doi.org/10.1038/ncomms7342

Ordiz, M.I., May, T.D., Mihindukulasuriya, K., Martin, J., Crowley, J., Tarr, P.I., Ryan, K., Mortimer, E., Gopalsamy, G. and Maleta, K., 2015. The effect of dietary resistant starch type 2 on the microbiota and markers of gut inflammation in rural Malawi children. Microbiome 3: 37 .

Pedersen, C., Gallagher, E., Horton, F., Ellis, R.J., Ijaz, U.Z., Wu, H., Jaiyeola, E., Diribe, O., Duparc, T., Cani, P.D., Gibson, G.R., Hinton, P., Wright, J., La Ragione, R. and Robertson, M.D., 2016. Host-microbiome interactions in human type 2 diabetes following prebiotic fibre (galacto-oligosaccharide) intake. British Journal of Nutrition 116: 1869-1877. https://doi.org/10.1017/ s0007114516004086

Qin, J., Li, R., Raes, J., Arumugam, M., Burgdorf, K.S., Manichanh, C., Nielsen, T., Pons, N., Levenez, F., Yamada, T., Mende, D.R., Li, J., Xu, J., Li, S., Li, D., Cao, J., Wang, B., Liang, H., Zheng, H., Xie, Y., Tap, J., Lepage, P., Bertalan, M., Batto, J.-M., Hansen, T., Le Paslier, D., Linneberg, A., Nielsen, H.B., Pelletier, E., Renault, P., SicheritzPonten, T., Turner, K., Zhu, H., Yu, C., Li, S., Jian, M., Zhou, Y., Li, Y., Zhang, X., Li, S., Qin, N., Yang, H., Wang, J., Brunak, S., Doré, J., Guarner, F., Kristiansen, K., Pedersen, O., Parkhill, J., Weissenbach, J., Meta, H.I.T.C., Antolin, M., Artiguenave, F., Blottiere, H., Borruel, N., Bruls, T., Casellas, F., Chervaux, C., Cultrone, A., Delorme, C., Denariaz, G., Dervyn, R., Forte, M., Friss, C., Van de Guchte, M., Guedon, E., Haimet, F., Jamet, A., Juste, C., Kaci, G., Kleerebezem, M., Knol, J., Kristensen, M., Layec, S., Le Roux, K., Leclerc, M., Maguin, E., Melo Minardi, R., Oozeer, R., Rescigno, M., Sanchez, N., Tims, S., Torrejon, T., Varela, E., De Vos, W., Winogradsky, Y., Zoetendal, E., Bork, P., Ehrlich, S.D. and Wang, J., 2010. A human gut microbial gene catalogue established by metagenomic sequencing. Nature 464: 59 .
Ramirez-Farias, C., Slezak, K., Fuller, Z., Duncan, A., Holtrop, G. and Louis, P., 2009. Effect of inulin on the human gut microbiota: stimulation of Bifidobacterium adolescentis and Faecalibacterium prausnitzii. British Journal of Nutrition 101: 541-550. https://doi. org/10.1017/s0007114508019880

Reid, G., Gaudier, E., Guarner, F., Huffnagle, G.B., Macklaim, J.M., Munoz, A.M., Martini, M., Ringel-Kulka, T., Sartor, B., Unal, R., Verbeke, K., Walter, J., 2010. Responders and non-responders to probiotic interventions: how can we improve the odds? Gut Microbes 1: 200-204. https://doi.org/10.4161/gmic.1.3.12013

Reimer, R.A., Willis, H.J., Tunnicliffe, J.M., Park, H., Madsen, K.L. and Soto-Vaca, A., 2017. Inulin-type fructans and whey protein both modulate appetite but only fructans alter gut microbiota in adults with overweight/obesity: a randomized controlled trial. Molecular Nutrition and Food Research 61: 1700484. https://doi.org/10.1002/ mnfr.201700484

Rinne, M.M., Gueimonde, M., Kalliomaki, M., Hoppu, U., Salminen, S.J. and Isolauri, E., 2005. Similar bifidogenic effects of prebiotic-supplemented partially hydrolyzed infant formula and breastfeeding on infant gut microbiota. FEMS Immunology and Medical Microbiology 43: 59-65. https://doi.org/10.1016/j. femsim.2004.07.005

Ritsema, T. and Smeekens, S., 2003. Fructans: beneficial for plants and humans. Current Opinion in Plant Biology 6: 223-230.

Roberfroid, M., Gibson, G.R., Hoyles, L., McCartney, A.L., Rastall, R., Rowland, I., Wolvers, D., Watzl, B., Szajewska, H., Stahl, B., Guarner, F., Respondek, F., Whelan, K., Coxam, V., Davicco, M.J., Leotoing, L., Wittrant, Y., Delzenne, N.M., Cani, P.D., Neyrinck, A.M. and Meheust, A., 2010. Prebiotic effects: metabolic and health benefits. British Journal of Nutrition 104, Suppl. 2: S1-63. https:// doi.org/10.1017/s0007114510003363

Saengthongpinit, W. and Sajjaanantakul, T., 2005. Influence of harvest time and storage temperature on characteristics of inulin from Jerusalem artichoke (Helianthus tuberosus L.) tubers. Postharvest Biology and Technology 37: 93-100.

Salonen, A., Lahti, L., Salojarvi, J., Holtrop, G., Korpela, K., Duncan, S.H., Date, P., Farquharson, F., Johnstone, A.M., Lobley, G.E., Louis, P., Flint, H.J. and De Vos, W.M., 2014. Impact of diet and individual variation on intestinal microbiota composition and fermentation products in obese men. ISME Journal 8: 2218-2230. https://doi. org/10.1038/ismej.2014.63

Schaafsma, G. and Slavin, J.L., 2014. Significance of inulin fructans in the human diet. Comprehensive Reviews in Food Science and Food Safety 14: 37-47. https://doi.org/10.1111/1541-4337.12119

Scholtens, P.A., Alles, M.S., Bindels, J.G., Van der Linde, E.G. Tolboom, J.J. and Knol, J., 2006. Bifidogenic effects of solid weaning foods with added prebiotic oligosaccharides: a randomised controlled clinical trial. Journal of Pediatric Gastroenterology and Nutrition 42: 553-559. https://doi.org/10.1097/01.mpg.0000221887.28877.c7

Sekirov, I., Russell, S.L., Antunes, L.C.M. and Finlay, B.B., 2010. Gut microbiota in health and disease. Physiological Reviews 90: 859-904. https://doi.org/10.1152/physrev.00045.2009 
Shetty, S.A., Hugenholtz, F., Lahti, L., Smidt, H. and de Vos, W.M., 2017. Intestinal microbiome landscaping: insight in community assemblage and implications for microbial modulation strategies. FEMS Microbiology Reviews 41: 182-199. https://doi.org/10.1093/ femsre/fuw045

Shetty, S.A., Zuffa, S., Bui, T.P.N., Aalvink, S., Smidt, H. and De Vos, W.M., 2018. Reclassification of Eubacterium hallii as Anaerobutyricum hallii gen. nov., comb. nov., and description of Anaerobutyricum soehngenii sp. nov., a butyrate and propionateproducing bacterium from infant faeces. Systematic and Evolutionary Microbiology 68: 3741-3746. https://doi.org/10.1099/ijsem.0.003041

Slavin, J., 2013. Fiber and prebiotics: mechanisms and health benefits. Nutrients 5: 1417-1435. https://doi.org/10.3390/nu5041417

Sloan, T.J., Jalanka, J., Major, G.A.D., Krishnasamy, S., Pritchard, S., Abdelrazig, S., Korpela, K., Singh, G., Mulvenna, C., Hoad, C.L., Marciani, L., Barrett, D.A., Lomer, M.C.E., De Vos, W.M., Gowland, P.A. and Spiller, R.C., 2018. A low FODMAP diet is associated with changes in the microbiota and reduction in breath hydrogen but not colonic volume in healthy subjects. PLoS ONE 13: e0201410. https://doi.org/10.1371/journal.pone.0201410

So, D., Whelan, K., Rossi, M., Morrison, M., Holtmann, G., Kelly, J.T., Shanahan, E.R., Staudacher, H.M. and Campbell, K.L., 2018. Dietary fiber intervention on gut microbiota composition in healthy adults: a systematic review and meta-analysis. American Journal of Clinical Nutrition 107: 965-983.

Soldi, S., Vasileiadis, S., Lohner, S., Uggeri, F., Puglisi, E., Molinari, P., Donner, E., Sieland, C., Decsi, T. and Sailer, M., 2019. Prebiotic supplementation over a cold season and during antibiotic treatment specifically modulates the gut microbiota composition of 3-6 yearold children. Beneficial Microbes 10: 253-263.

Sonnenburg, E.D., Smits, S.A., Tikhonov, M., Higginbottom, S.K., Wingreen, N.S. and Sonnenburg, J.L., 2016. Diet-induced extinctions in the gut microbiota compound over generations. Nature 529: 212-215. https://doi.org/10.1038/nature16504.

Stephen, A.M., Champ, M.M., Cloran, S.J., Fleith, M., Van Lieshout, L., Mejborn, H. and Burley, V.J., 2017. Dietary fibre in Europe: current state of knowledge on definitions, sources, recommendations, intakes and relationships to health. Nutrition Research Reviews 30: 149-190. https://doi.org/10.1017/s095442241700004x

Stulberg, E., Fravel, D., Proctor, L.M., Murray, D.M., LoTempio, J., Chrisey, L., Garland, J., Goodwin, K., Graber, J., Harris, M.C., Jackson, S., Mishkind, M., Porterfield, D.M. and Records, A., 2016. An assessment of US microbiome research. Nature Microbiology 1: 15015 .

Swennen, K., Courtin, C.M., Lindemans, G.C.J.E. and Delcour, J.A., 2006. Large-scale production and characterisation of wheat bran arabinoxylooligosaccharides. Journal of the Science of Food and Agriculture 86: 1722-1731. https://doi.org/10.1002/jsfa.2470

Tandon, D., Haque, M.M., Gote, M., Jain, M., Bhaduri, A., Dubey, A.K. and Mande, S.S., 2019. A prospective randomized, double-blind, placebo-controlled, dose-response relationship study to investigate efficacy of fructo-oligosaccharides (FOS) on human gut microflora. Scientific Reports 9: 5473.
Ten Bruggencate, S.J., Bovee-Oudenhoven, I.M., Lettink-Wissink, M.L., Katan, M.B. and Van der Meer, R., 2006. Dietary fructooligosaccharides affect intestinal barrier function in healthy men. Journal of Nutrition 136: 70-74. https://doi.org/10.1093/ jn/136.1.70

Tims, S., Snel, J., Ten Bruggencate, S.J.M., Van Schalkwijk, S., Timmerman, H. and Boekhorst, J., 2016. Fructo-oligosaccharides induce a shift from Bacteroidetes to Bifidobacterium and restructure gut microbiota in healthy volunteers. PhD-thesis, Wageningen University, Wageningen, the Netherlands.

Torres, D.P.M., Gonçalves, M.d.P.F., Teixeira, J.A. and Rodrigues, L.R., 2010. Galacto-oligosaccharides: production, properties, applications, and significance as prebiotics. Comprehensive Reviews in Food Science and Food Safety 9: 438-454. https://doi.org/10.1111/j.15414337.2010.00119.x

Tuohy, K.M., Finlay, R.K., Wynne, A.G. and Gibson, G.R., 2001a. A human volunteer study on the prebiotic effects of HP-inulin - faecal bacteria enumerated using fluorescent in situ hybridisation (FISH). Anaerobe 7: 113-118. https://doi.org/10.1006/anae.2001.0368

Tuohy, K.M., Kolida, S., Lustenberger, A.M. and Gibson, G.R., 2001b. The prebiotic effects of biscuits containing partially hydrolysed guar gum and fructo-oligosaccharides - a human volunteer study. British Journal of Nutrition 86: 341-348. https://doi.org/10.1079/ bjn2001394

Upadhyaya, B., McCormack, L., Fardin-Kia, A.R., Juenemann, R., Nichenametla, S., Clapper, J., Specker, B. and Dey, M., 2016. Impact of dietary resistant starch type 4 on human gut microbiota and immunometabolic functions. Scientific Reports 6: 28797-28797. https://doi.org/10.1038/srep28797

Valdes, A.M., Walter, J., Segal, E. and Spector, T.D., 2018. Role of the gut microbiota in nutrition and health. BMJ 361: k2179.

Van Craeyveld, V., Swennen, K., Dornez, E., Van de Wiele, T., Marzorati, M., Verstraete, W., Delaedt, Y., Onagbesan, O., Decuypere, E., Buyse, J., De Ketelaere, B., Broekaert, W.F., Delcour, J.A. and Courtin, C.M., 2008. Structurally different wheatderived arabinoxylooligosaccharides have different prebiotic and fermentation properties in rats. Journal of Nutrition 138: 2348-2355. https://doi.org/10.3945/jn.108.094367

Van de Wouw, M., Boehme, M., Lyte, J.M., Wiley, N., Strain, C., O'Sullivan, O., Clarke, G., Stanton, C., Dinan, T.G. and Cryan, J.F., 2018. Short-chain fatty acids: microbial metabolites that alleviate stress-induced brain-gut axis alterations. Journal of Physiology 596: 4923-4944. https://doi.org/10.1113/jp276431

Van der Beek, C.M., Canfora, E.E., Kip, A.M., Gorissen, S.H., Damink, S.W.O., Van Eijk, H.M., Holst, J.J., Blaak, E.E., Dejong, C.H. and Lenaerts, K., 2018. The prebiotic inulin improves substrate metabolism and promotes short-chain fatty acid production in overweight to obese men. Metabolism 87: 25-35.

Van Loo, J., Coussement, P., De Leenheer, L., Hoebregs, H. and Smits, G., 1995. On the presence of inulin and oligofructose as natural ingredients in the western diet. Critical Reviews in Food Science and Nutrition 35: 525-552. https://doi.org/10.1080/10408399509527714 Vandeputte, D., Falony, G., Vieira-Silva, S., Wang, J., Sailer, M., Theis, S., Verbeke, K. and Raes, J., 2017. Prebiotic inulin-type fructans induce specific changes in the human gut microbiota. Gut 66: 1968-1974. https://doi.org/10.1136/gutjnl-2016-313271 
Venkataraman, A., Sieber, J.R., Schmidt, A.W., Waldron, C., Theis, K.R. and Schmidt, T.M., 2016. Variable responses of human microbiomes to dietary supplementation with resistant starch. Microbiome 4: 33. https://doi.org/10.1186/s40168-016-0178-x

Vital, M., Howe, A., Bergeron, N., Krauss, R.M., Jansson, J.K. and Tiedje, J.M., 2018. Metagenomic insights into the degradation of resistant starch by human gut microbiota. Applied and Environmental Microbiology 84: e01562-01518.

Vogt, L.M., Elderman, M.E., Borghuis, T., De Haan, B.J., Faas, M.M. and De Vos, P., 2017. Chain length-dependent effects of inulin-type fructan dietary fiber on human systemic immune responses against hepatitis-B. Molecular Nutrition and Food Research 61: 1700171.

Walker, A.W., Ince, J., Duncan, S.H., Webster, L.M., Holtrop, G., Ze, X., Brown, D., Stares, M.D., Scott, P., Bergerat, A., Louis, P., McIntosh, F., Johnstone, A.M., Lobley, G.E., Parkhill, J. and Flint, H.J., 2011. Dominant and diet-responsive groups of bacteria within the human colonic microbiota. ISME Journal 5: 220-230. https:// doi.org/10.1038/ismej.2010.118

Walker, A.W., Martin, J.C., Scott, P., Parkhill, J., Flint, H.J. and Scott, K.P., 2015. 16S rRNA gene-based profiling of the human infant gut microbiota is strongly influenced by sample processing and PCR primer choice. Microbiome 3: 26.

Walton, G.E., Lu, C., Trogh, I., Arnaut, F. and Gibson, G.R., 2012. A randomised, double-blind, placebo controlled cross-over study to determine the gastrointestinal effects of consumption of arabinoxylan-oligosaccharides enriched bread in healthy volunteers. Journal of Nutrition 11: 36. https://doi.org/10.1186/1475-2891-11-36

Wang, Y., Ames, N.P., Tun, H.M., Tosh, S.M., Jones, P.J. and Khafipour, E., 2016. High molecular weight barley $\beta$-glucan alters gut microbiota toward reduced cardiovascular disease risk. Frontiers in Microbiology 7: 129.

Watson, A.W., Houghton, D., Avery, P.J., Stewart, C., Vaughan, E.E., Meyer, P.D., De Bos Kuil, M.J., Weijs, P.J. and Brandt, K., 2019. Changes in stool frequency following chicory inulin consumption, and effects on stool consistency, quality of life and composition of gut microbiota. Food Hydrocolloids 96: 688-698.

Whisner, C.M., Martin, B.R., Nakatsu, C.H., Story, J.A., MacDonaldClarke, C.J., McCabe, L.D., McCabe, G.P. and Weaver, C.M., 2016. Soluble corn fiber increases calcium absorption associated with shifts in the gut microbiome: a randomized dose-response trial in free-living pubertal females. British Journal of Nutrition 146: 1298-1306. https://doi.org/10.3945/jn.115.227256
Williams, P.A. and Phillips, G., 2009. Gum arabic. In: Handbook of hydrocolloids, $2^{\text {nd }}$ edition. Elsevier, New York, NY, USA, pp. 252-273.

Wong, C., Harris, P.J. and Ferguson, L.R., 2016. Potential benefits of dietary fibre intervention in inflammatory bowel disease. International Journal of Molecular Sciences 17: 919. https://doi. org/10.3390/ijms17060919

Wood, P.J., 2007. Cereal $\beta$-glucans in diet and health. Journal of Cereal Science 46: 230-238.

Wu, W.T., Cheng, H.C. and Chen, H.L., 2011. Ameliorative effects of konjac glucomannan on human faecal beta-glucuronidase activity, secondary bile acid levels and faecal water toxicity towards Caco2 cells. British Journal of Nutrition 105: 593-600. https://doi. org/10.1017/s0007114510004009

Yang, D., Yuan, Y., Wang, L., Wang, X., Mu, R., Pang, J., Xiao, J. and Zheng, Y., 2017. A review on konjac glucomannan gels: microstructure and application. International Journal of Molecular Sciences 18: 2250.

Yang, J., Summanen, P.H., Henning, S.M., Hsu, M., Lam, H., Huang, J., Tseng, C.H., Dowd, S.E., Finegold, S.M., Heber, D. and Li, Z., 2015. Xylooligosaccharide supplementation alters gut bacteria in both healthy and prediabetic adults: a pilot study. Frontiers in Physiology 6: 216. https://doi.org/10.3389/fphys.2015.00216

Zeevi, D., Korem, T., Zmora, N., Israeli, D., Rothschild, D., Weinberger, A., Ben-Yacov, O., Lador, D., Avnit-Sagi, T., Lotan-Pompan, M., Suez, J., Mahdi, J.-á., Matot, E., Malka, G., Kosower, N., Rein, M., Zilberman-Schapira, G., Dohnaloveí, L., Pevsner-Fischer, M., Bikovsky, R., Halpern, Z., Elinav, E. and Segal, E., 2015. Personalized nutrition by prediction of glycemic responses. Cell 163: 1079-1094. https://doi.org/10.1016/j.cell.2015.11.001

Zhang, L., Ouyang, Y., Li, H., Shen, L., Ni, Y., Fang, Q., Wu, G., Qian, L., Xiao, Y. and Zhang, J., 2019. Metabolic phenotypes and the gut microbiota in response to dietary resistant starch type 2 in normal-weight subjects: a randomized crossover trial. Scientific Reports 9: 4736.

Zhao, L., Zhang, F., Ding, X., Wu, G., Lam, Y.Y., Wang, X., Fu, H., Xue, X., Lu, C. and Ma, J., 2018. Gut bacteria selectively promoted by dietary fibers alleviate type 2 diabetes. Science 359: 1151-1156. 
